ECCOMAS

Proceedia
COMPDYN 2021

$8^{\text {th }}$ ECCOMAS Thematic Conference on Computational Methods in Structural Dynamics and Earthquake Engineering M. Papadrakakis, M. Fragiadakis (eds.) Streamed from Athens, Greece, 28 - 30 June 2021

\title{
SEISMIC VULNERABILITY OF MASONRY HISTORICAL STRUCTURES: A SIMPLE ADAPTIVE NURBS FE APPROACH FOR THE LIMIT AND THE SUBSEQUENT NON-LINEAR STATIC ANALYSIS WITH FEW DOFS
}

\author{
Nicola Grillanda ${ }^{1}$ and Gabriele Milani ${ }^{1}$ \\ ${ }^{1}$ Department of Architecture, Built Environment and Construction Engineering (ABC), Polytechnic \\ University of Milan \\ Piazza Leonardo Da Vinci 32, 20133 Milan (Italy) \\ email: nicola.grillanda@polimi.it, gabriele.milani@polimi.it
}

\begin{abstract}
The present contribution deals with an innovative evaluation of the vulnerability and static seismic behavior of existing masonry structures and monumental buildings. For a given masonry construction, a discretization through few NURBS surfaces is realized. NURBS surfaces are converted into shell elements which are assumed rigid and infinitely resistant. The nonlinearities typical of the masonry material (almost no tensile strength, frictional behavior in shear, and relatively larger resistance in compression) are imposed at interfaces between adjacent elements, which represent in this way possible fracture lines. Once defined a horizontal load configuration, an adaptive upper bound limit analysis is applied. As final result, the collapse mechanism and the collapse load multiplier are found. Then, to provide the complete non-linear structural response, a FE model composed of elastic elements representing macroblocks and non-linear contact-based interfaces or plastic damaging strips corresponding to the cracks is derived. On such model, static non-linear analyses can be performed easily at a fraction of the computational burden needed by standard approaches. Several examples including masonry churches, vaults, and buildings are presented. Finally, a novel limit analysis computational technique based on a discretization through NURBS solid elements is introduced and future perspectives of the research are drawn.
\end{abstract}

Keywords: Masonry, seismic vulnerability, NURBS, limit analysis, non-linear analysis. 


\section{INTRODUCTION}

The prediction of the load bearing capacity and ultimate displacements in the framework of a displacement-based design for existing masonry structures and monumental buildings is a very difficult task and at present a hot topic for the specialized scientific community, especially for earthquake prone masonry countries.

As a matter of fact, a huge amount of different modelling strategies have been developed in the last decades [1] to deal with the multitude of challenges that characterize the analysis of such structures in the non-linear range. Indeed, masonry is characterized by heterogeneity, strongly non-linear behavior even at low levels of both horizontal and vertical loads, anisotropic response, complex geometries and an infinite variability of the textures.

Classically, we can distinguish two main analysis approaches for masonry structures subjected to horizontal loads [2], namely (i) limit analysis-based and (ii) incremental-evolutive approaches.

Numerical techniques based on limit analysis are quite diffused nowadays because it is well-known their reliability for the realistic determination of both collapse mechanisms and ultimate load carrying capacity. Limit analysis applied to masonry has a long tradition and is basically due to the seminal work by Heyman [3]. In the last four decades, many different approaches have been developed grounded on the utilization of both the lower bound [4]-[8] and the upper bound [9]-[11] theorem, removing also in some cases the associativity of the flow rule. When embedded in a FE formulation, limit analysis becomes very intuitive in its upper bound formulation and kinematic approaches are generally preferred in the literature [12]-[14]. Within the FE upper bound formulation, different models have been proposed, assuming that the inelastic deformation occurs only inside elements, only at the interfaces between adjoining elements or on both interfaces and elements, as firstly proposed in [15] for geotechnical problems. When the plastic dissipation is constrained to occur only on interfaces, then the problem becomes strongly mesh dependent and either remeshing or mesh adaptation algorithms are needed [16]. The advantage is that the number of variables is limited and, if the adaptation scheme is efficient, the computational burden remains rather limited [17]-[19]. However, as well known limit analysis typically does not provide any information regarding displacements, although this would be essential in a displacement-based design, which is considered the standard for any seismic analysis [20].

Incremental-evolutive approaches are widely utilized tools for the step-by-step investigation of the structural equilibrium in nonlinear iterative analysis frameworks, often used in pushover analyses for the seismic assessment of masonry structures [21]. These approaches can be used within three classic modelling strategies that proved to be effective for masonry structures:

- Macro-element models or simplified models in general (see e.g. [22]-[27]), widely used in common engineering practice due to their simplicity, although typically limited to ordinary buildings and not applicable for complex monumental structures;

- Block-based models (see e.g. [28]-[32]) where masonry is modelled block-by-block (typically into Finite Elements) and the interaction between blocks can be accounted for through various formulations, being the most diffused the utilization of mortar interfaces. Although potentially highly accurate, their main drawback is the huge computational effort needed even for small and medium size structures;

- Continuum models (see e.g. [33]-[35]) where masonry is modelled through a deformable continuum and the constitutive law can be defined directly or through a multi-scale framework. These models, although interesting and potentially very effective, could be computationally expensive or could find difficulties in representing the post-peak response due to 
convergence issues, as well as the collapse mechanism predicted could be, in general, not fully clear and somewhat smeared [35].

- Discrete element models -or restricting the family of the approaches proposed, Distinct Element Methods DEMs- (as for instance those presented in [36]-[44] without being exhaustive) where masonry is modelled with rigid or elastic blocks and all non-linearity is lumped on joints typically assumed with a cohesive frictional behaviour [43][44]. Such approach is conceived mainly for Non Linear Dynamic Analyses NLDAs [45]-[47] but it can be adapted also to static non linear analyses, or in presence of foundation settlements, albeit requiring typically huge computational efforts. There are obviously other important drawbacks that cannot be summarized in few words in this introduction, but it is interesting to point out how they have recently inspired the implementation of FEM combined with DEM for large scale computations (see for instance [48]-[49]).

Accordingly, both limit analysis-based and incremental-evolutive approaches present either advantages or disadvantages, and their coupling would represent a favourable solution. The research initially conceived by one of the authors of this paper [50] represented a first attempt to couple limit analysis to displacement-based strategies. In particular, in [50] the collapse mechanism deduced by a genetic algorithm-based GA adaptive limit analysis has been used in a pushover-based framework using two different approaches to introduce nonlinearities in the model. The first one considered 3D plastic damaging strips governed by a nonlinear continuum constitutive law, while the second exploited zero-thickness contact-based interfaces governed by a cohesive-frictional contact behaviour. Both approaches proved a good performance in simulating not only the separate in- and out-of-plane behaviour of masonry structures, but also than of full 3D buildings, having the advance of requiring for such analyses a considerably low computational demand.

Returning to deal with classic limit analysis, it can be affirmed that its adoption, when the procedure grounds basically on the pioneering paper by Heyman [3] is still very suitable; it is not a case indeed that it has been recently applied in a very successful manner, because the approach is very straightforward, relatively simple and quite accurate in predicting load carrying capacities and failure mechanisms. This is probably the reason why many other researchers developed in the last four decades interesting different limit-analysis procedures, in the majority of the cases basing on a FE discretization (that goes well with limit analysis) -both homogeneous and heterogeneous-, using less the static theorem [4]-[8] and slightly more the kinematic theorem [51]-[56] approach. This is not a case; it is indeed opinion of the authors that, from an implementation point of view, limit analysis procedures which use finite elements (FEs) are typically easier to implement when based on the upper bound theorem, i.e. in a kinematic framework. For cohesive-frictional materials (e.g. masonry) the solution can be found easily also in presence of a non associated flow rule and therefore it appears particularly flexible, especially in all those cases were dissipation occurs only on interfaces between contiguous elements, i.e. failure is due to the formation of a kinematic chain formed by large rigid blocks, an intuition which follows the idea originally proposed in [57]. Nowadays, limit analysis-based solutions are considered trustworthy to investigate collapse mechanisms and the ultimate load in masonry structures [3].

The present paper discusses the following important key issues related to an adaptive limit analysis of existing masonry buildings in general (including also masonry aggregates), masonry curved structures and monumental buildings;

1) The most suitable and stable adaptive limit analysis algorithm to use to obtain results quickly with a high confidence on the correctness of the estimated collapse accelerations and failure mechanisms. 
2) The flexibility of the approach, intended as its utilization in a variety of different limit analysis problems, which includes also the possibility to take into account the orthotropy of the material (when present), the possible presence of multi-leaf walls, double curvature structures or the analysis of complex masonry aggregates exhibiting good or bad interlocking at the intersection between perpendicular walls, also in presence of any kind of strengthening device, such as tie rods, FRP strips, continuous FRCM reinforcement, etc.

3) The extension to non-linear static analyses, i.e. a newly conceived two-step methodology where ultimate displacements can be predicted after a preliminary limit analysis. The main idea of the procedure proposed is shown schematically in Figure 1. For a given masonry construction, a discretization through few NURBS surfaces is realized. NURBS surfaces are converted into shell elements which are assumed rigid and infinitely resistant. The non-linearities typical of the masonry material (almost no tensile strength, frictional behavior in shear, and relatively larger resistance in compression) are imposed at interfaces between adjacent elements, which represent in this way possible fracture lines. Once defined a horizontal load configuration, an adaptive upper bound limit analysis is applied. As final result, the collapse mechanism and the collapse load multiplier are found. Then, to provide the complete non-linear structural response, a FE model composed of elastic elements representing macro-blocks and nonlinear contact-based interfaces or plastic damaging strips corresponding to the cracks is derived. On such model, static non-linear analyses can be performed easily at a fraction of the computational burden needed by standard approaches.
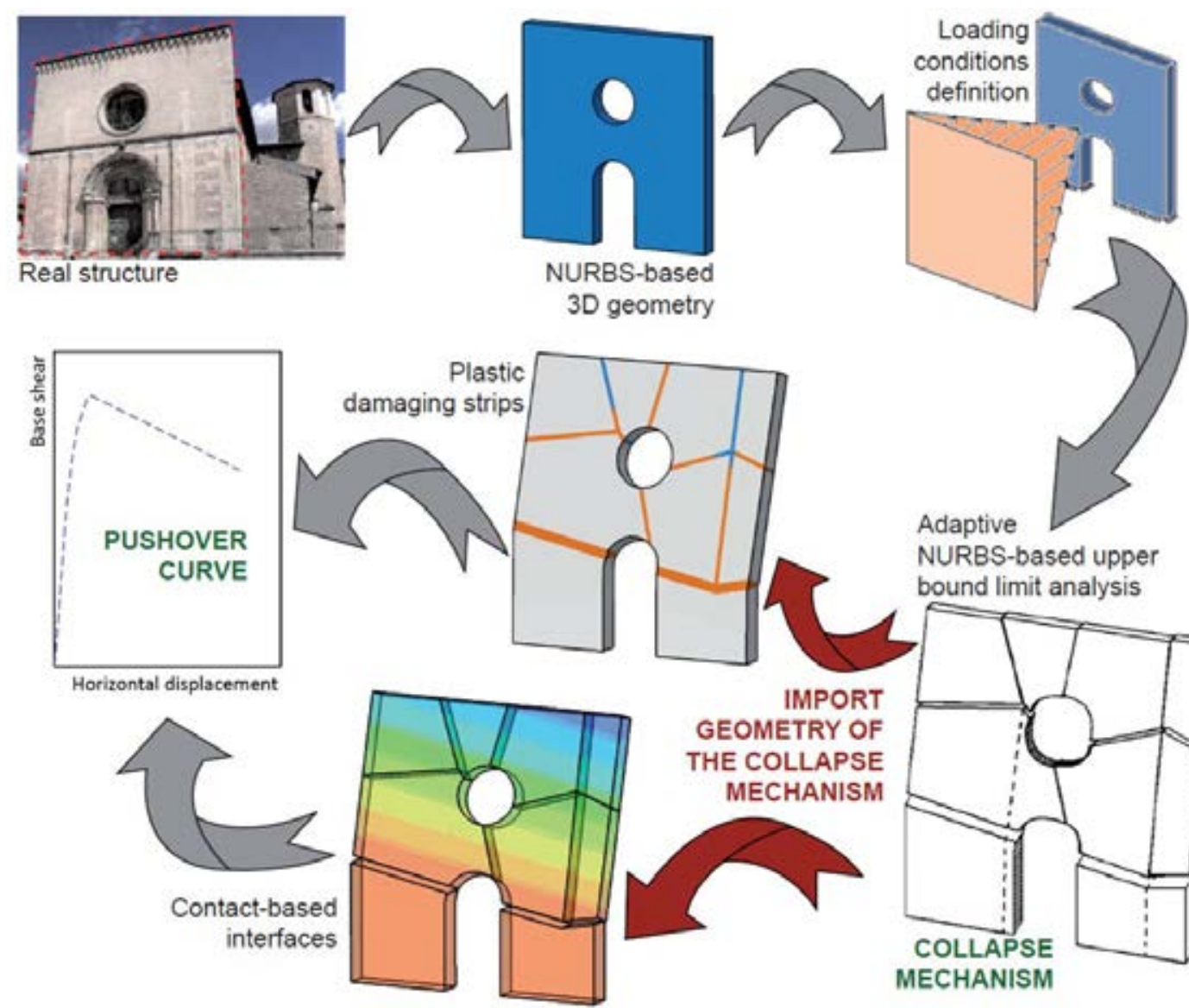

NURBS-based upper bound limit analysis interfaces
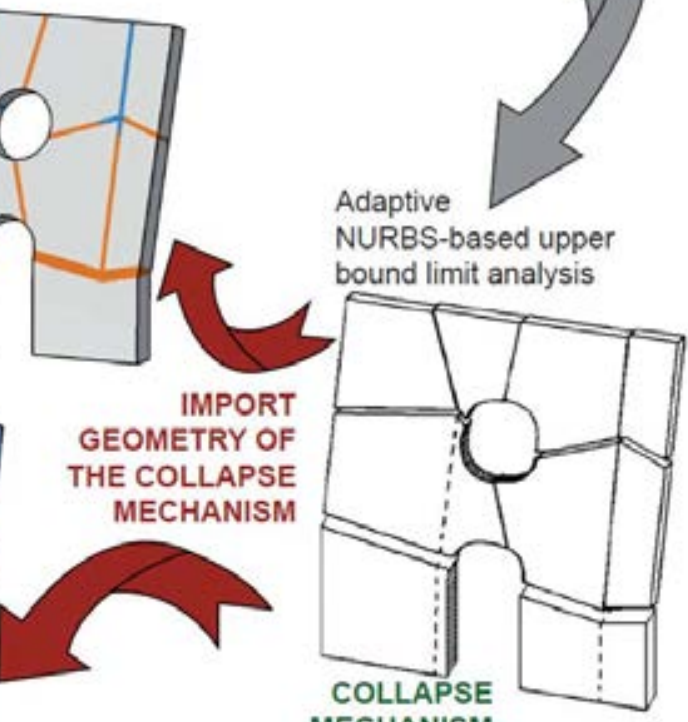

Figure 1. two-step approach used to provide quickly pushover curves for complex masonry structures. 
In the present paper, several examples including masonry churches, vaults, and buildings are discussed in detail. Finally, a novel limit analysis computational technique based on a discretization through NURBS solid elements is introduced and future perspectives of the research are drawn.

\section{THE THEORETICAL METHOD ADOPTED}

In the present Section, the main features of the theoretical model adopted for the adaptive limit analysis and the subsequent simplified pushover analysis are recalled and commented, discussing also the efficiency of different meta-heuristic approaches used for the mesh adaptation.

\subsection{Adaptive NURBS-based upper bound limit analysis}

For a given masonry structure, a model composed by curved or planar NURBS surfaces is realized within the Rhinoceros environment. NURBS surfaces (Non-Uniform Rational Bezier Spline [58]) are parametric surfaces whose basis functions are piecewise polynomial rational functions obtained starting from the traditional spline basis function. In this approach, NURBS properties are used to both represent exactly curved geometries and facilitate mesh adaptation procedures.

The NURBS model of the whole masonry structure is imported within MATLAB, where each surface is here converted into a $3 \mathrm{D}$ shell element through the definition of a thickness value. By using the properties of NURBS, a mesh can be defined by subdividing each initial surface into few trimmed surfaces: each one generates a single element that is still a NURBS surface and the overall geometry is not altered. Elements are supposed to behave as rigid blocks with internal dissipation allowed only along their interfaces. With the aim of finding a failure mechanism constituted exclusively by macro-blocks, the NURBS elements constitute the macro-blocks involved in the mechanism and interfaces are possible fracture lines or hinges.

An upper bound limit analysis is applied. Given a load configuration $\left[\mathbf{q}_{0}, \lambda \mathbf{q}\right]$, in which $\mathbf{q}_{0}$ are permanent loads and $\mathbf{q}$ are live loads depending on a multiplier $\lambda$, a mechanism involving the few rigid elements composing the initial mesh can be identified by solving a linear programming problem. The mechanism is described by a velocity field $\dot{\mathbf{u}}$ that contains the six velocity components (three translational and three rotational) of each centroid of a NURBS macro-block, which at the edges exhibits discontinuities (i.e. velocity jumps) with respected to the contiguous elements. To properly quantify the velocity jumps, rigid-plastic interfaces are defined at the common boundaries between adjacent elements. Each interface is discretized through collocation points to which the associative flow rule is imposed:

$$
\Delta \tilde{\dot{\mathbf{u}}}=\dot{\lambda} \frac{\partial f}{\partial \boldsymbol{\sigma}}
$$

where $\Delta \tilde{\dot{\mathbf{u}}}$ are the velocity jumps defined in the local reference system, $\dot{\lambda}$ are the nonnegative plastic multipliers, $\boldsymbol{\sigma}$ is the stress vector, and $f$ is the linearized three-dimensional yield domain defined in the space of the local stress. For the masonry material, $f$ can be represented by using a three-dimensional Mohr-Coulomb failure criterion defined through a cohesion value $c$ and a friction angle $\varphi$. A tension cut-off and a linear cap in compression are included to limit respectively the maximum tensile strength $f_{\mathrm{t}}$, otherwise equal to $c / \tan (\varphi)$, and the maximum compression strength $f_{\mathrm{c}}$ that masonry can undergo. The failure surface can be in any case changed at user's discretion, for instance utilizing the homogenization theory in the rigid plastic case to take into account in a rigorous manner orthotropy [59]. Alternatively, to reproduce the orthotropic behavior of masonry, a much more straightforward strategy is to 
assign two different sets of resistance values along two orthogonal directions of each NURBS surface (e.g. following the directions of bed and head joints): for each inclined interface, a Mohr-Coulomb domain is thus determined by combining the resistance values proportionally to the inclination angle.

Once defined the internal and the external power in reference to the overall vector of unknowns $\mathbf{x}=[\dot{\mathbf{u}}, \dot{\lambda}]$, the linear programming problem that solves the upper-bound formulation is summarized as follows:

$$
\text { min } \lambda=\mathbf{c}^{T} \mathbf{x} \text { such that }\left\{\begin{array}{c}
\mathbf{A x}=\mathbf{b} \\
\dot{\lambda} \geq \mathbf{0}
\end{array}\right.
$$

in which $\mathbf{A}$ is the global matrix of constraints (geometric, compatibility, and normality condition), $\mathbf{b}$ is the vector of known terms in the equality equations (basically a zero-vector with a unitary value as the last term), and $\mathbf{c}$ is the vector of coefficients derived from the Principle of Virtual Powers. The solution vector $\mathbf{x}$ contains the discontinuous velocity field that describes the mechanism obtained starting from the adopted mesh. Eventually, the linear programming problem can be modified into a sequential linear programming to take into account a non-associative behavior in shear (see [51]).

However, the use of a reduced number of macro-elements makes the problem highly meshdependent. According to the upper bound theorem of limit analysis, the collapse load multiplier is the minimum of the kinematic load multipliers and it is associated to the real collapse mechanism, which is properly identified only if the interfaces between adjacent elements coincide with the real position of fracture lines. Therefore, a procedure of mesh adaptation is finally applied: the initial mesh is iteratively adjusted until the absolute minimum of the kinematic load is found. For this operation, a meta-heuristic approach is used. Among the several available meta-heuristic algorithm [52], a Genetic Algorithm (GA) is generally applied, because considered sufficiently stable and reliable, as demonstrated in the following Section.

A representative scheme of adaptive limit analysis procedure (step 1 of Figure 1) is depicted schematically in Figure 2. This limit analysis procedure has been used to study several typologies of masonry structures in the last years by the authors, ranging from in-plane and outof-plane loaded panels to double curvature structures and masonry aggregates [18][19][51]$[56]$.

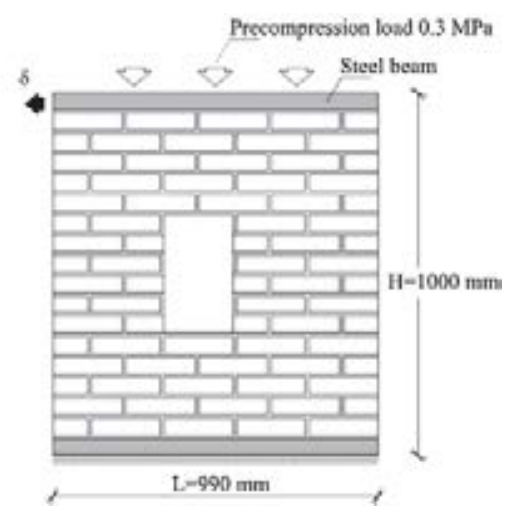

(a)

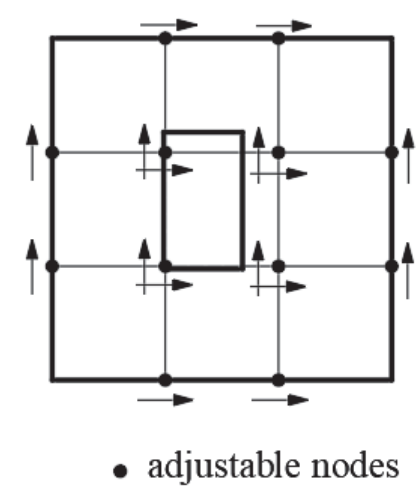

(b)

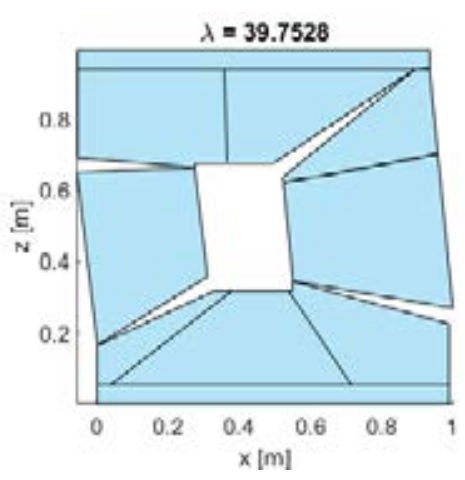

(c)

Figure 2. Adaptive upper bound limit analysis tool: (a) original geometry and load condition, (b) NURBS model with initial mesh, (c) collapse mechanism and collapse load multiplier. 


\subsection{Efficiency test for different meta-heuristic approaches for double curvature struc- tures}

The adaptive meta-heuristic approach previously mentioned has been tested on 4 double curvature structures utilizing 4 different algorithms in [52], namely using a specifically devised Prey Predator Algorithm (PPA), a Particle Swarm Optimization (PSO) Algorithm, a Firefly Algorithm (FA) and a specifically crafted Genetic Algorithm (GA). The reader interested into the details of the procedures adopted is referred to [52] for the sake of conciseness. In particular, here it is worth mentioning that the 4 benchmarks considered are a circular skew arch (test \#1), a parabolic straight arch (test \#2), a parabolic skew barrel vault (test \#3) and a ribbed cross vault (test \#4). Here we focus almost exclusively on test \#3, i.e. on the parabolic skew barrel vault, see Figure 3, for the sake of conciseness. The skew geometry forces the vault to fail non-symmetrically, displaying a mixed interaction of bending and torsional deformation modes. Therefore, the NURBS mesh of the vaulted surface is generated by four moving interfaces in the parameters space. As it can be easily predicted, the failure mechanism is more complex than a failure mechanism formed by four hinges as it occurs for straight arches. In particular, interfaces are not anymore constrained to remain orthogonal to the vault shape: in fact, they can rotate, so that the placement of each interface in the parameters space is governed by two parameters (i.e. the location of the yield lines extremes). It follows that the problem at hand is governed by eight parameters, as depicted in Figure 3(b). Therefore, the NURBS mesh of the vaulted surface is generated by eight moving interfaces in the parameters space. Nonlinear finite element analyses on this case study have been performed in [60] and they are used for comparison purposes. A population of 40 individuals has been adopted in all the meta-heuristics approaches. The number of total iterations is 50. Figure 4(a) depicts convergence plots for the 4 discussed meta-heuristic algorithms, whereas Figure 4 (b-c) illustrate the computational time needed to solve the problem. Similarly to the other benchmarks treated in [52] (i.e tests \#1, 2 and 4), PPA seems to guarantee a slightly faster convergence to the optimal solution when compared to the other three proposed meta-heuristic algorithms; furthermore, the error in the estimation of the collapse load multiplier is less than $5 \%$ after only 7 iterations, computed in 82 seconds. However, in general and also in this case, the performance of PPA is approximately equivalent to that provided by GA algorithm, which is able to furnish a very good approximation of the final solution after only 11 iterations. Table 1 summarizes the results in terms of computational time, number of iterations and number of function evaluations required for all the benchmarks discussed in [52]. Finally Figure 5 and Figure 6 show respectively the last iteration crack patterns associated to the collapse mechanisms for the four examples discussed in [52] and a comparison between the collapse mechanisms obtained by means of the proposed meta-heuristic NURBS-based limit analysis schemes and the ones obtained in the literature through both homogenized finite element limit analysis and experiments.

From the numerical tests carried out in [52], it can be affirmed that all meta-heuristic approaches are able to furnish engineering meaningful results at a fraction of standard FE limit analysis computations carried out with many elements. However, GA seems globally slightly more efficient and always in agreement with experimental evidences: such reasons are at the base of the preference given to GA in the two-step numerical procedure proposed in this work. 


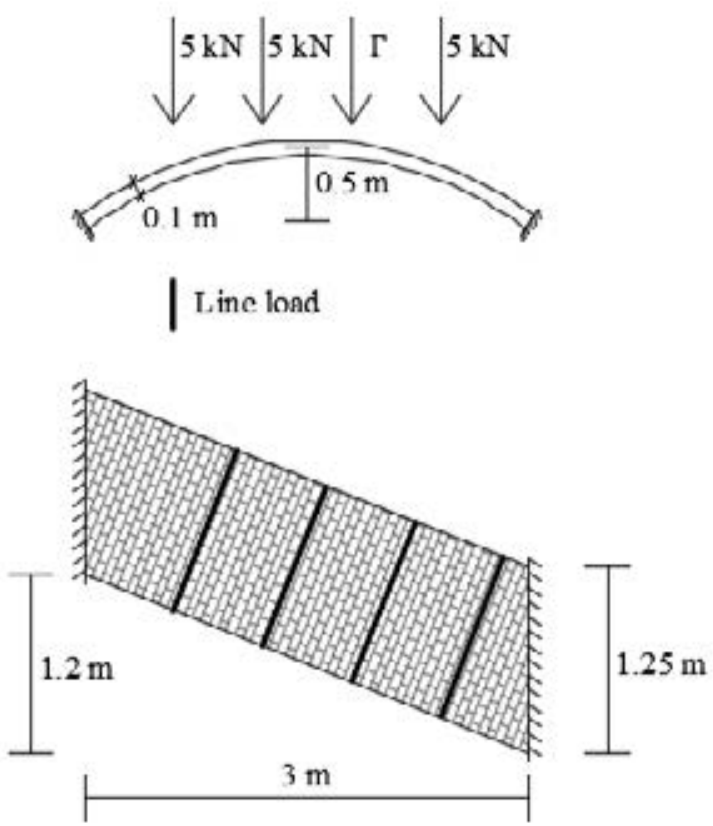

(a)

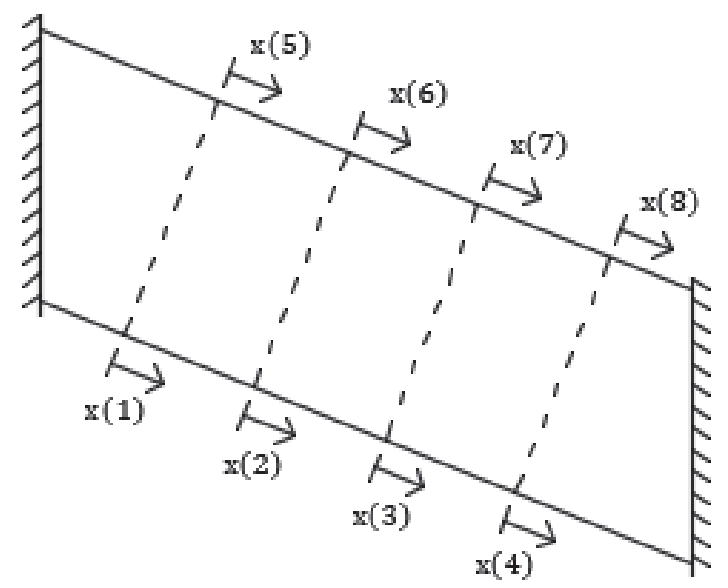

(b)

Figure 3. Skew barrel vault: (a) geometry and load condition, (b) eight parameters describing collapse mechanism.

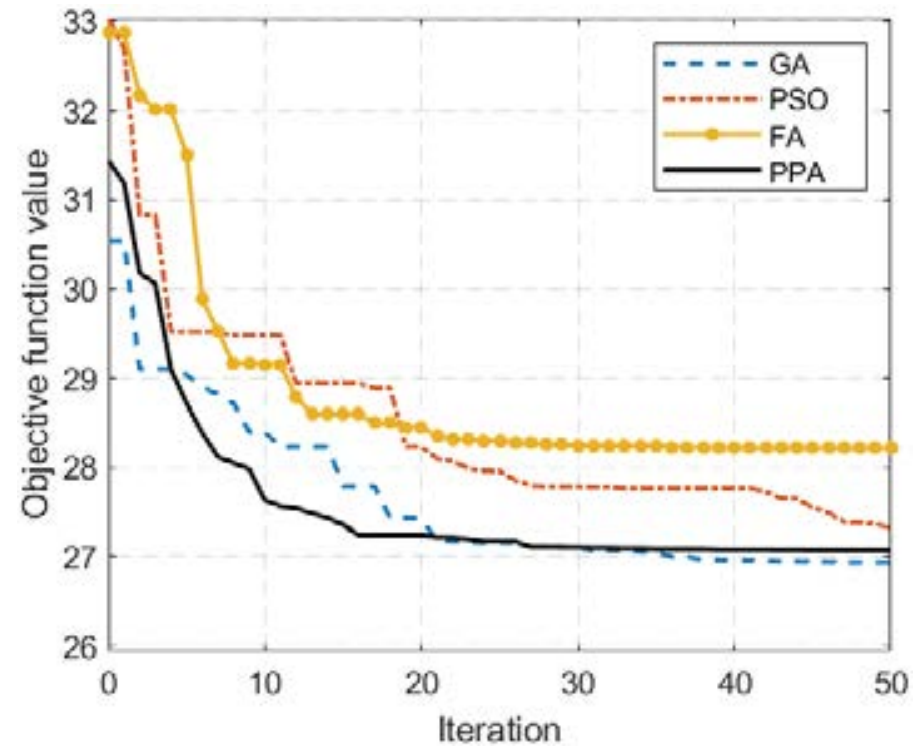

(a)

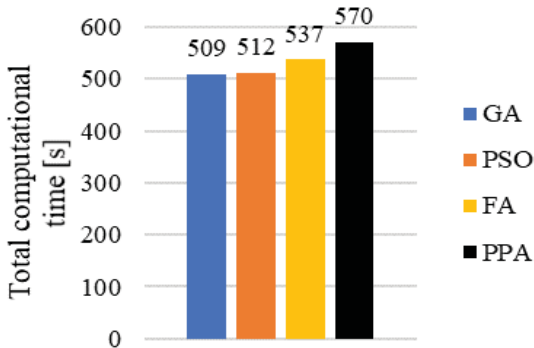

(b)

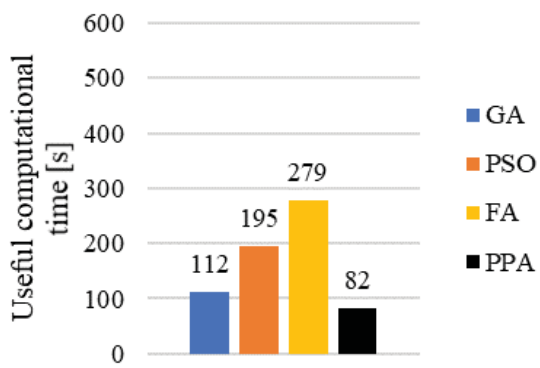

(c)

Figure 4. Skew barrel vault: comparison between the four different proposed meta-heuristic schemes; (a) convergence plots, (b) total computational time and (c) time spent for reaching the optimal solution within a 5\% error. 


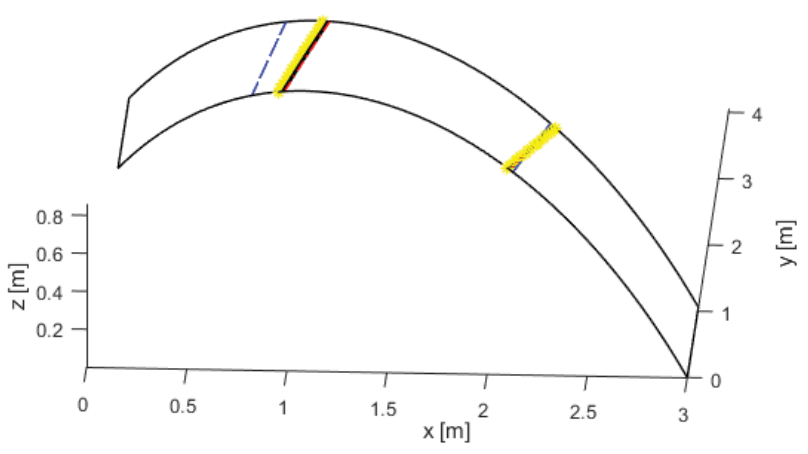

(a) test \#1

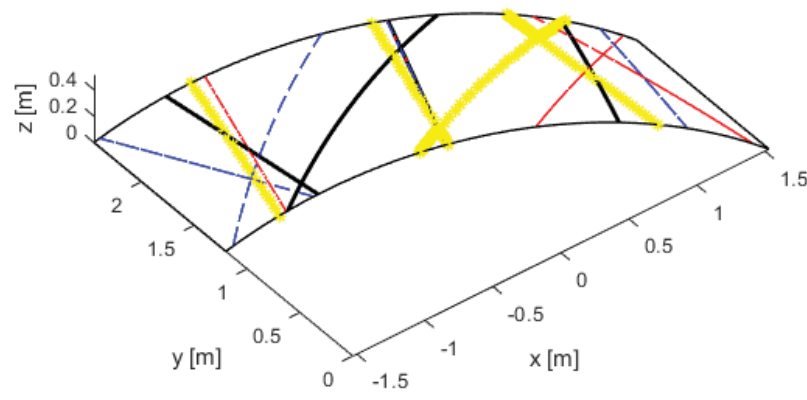

(c) test \#3

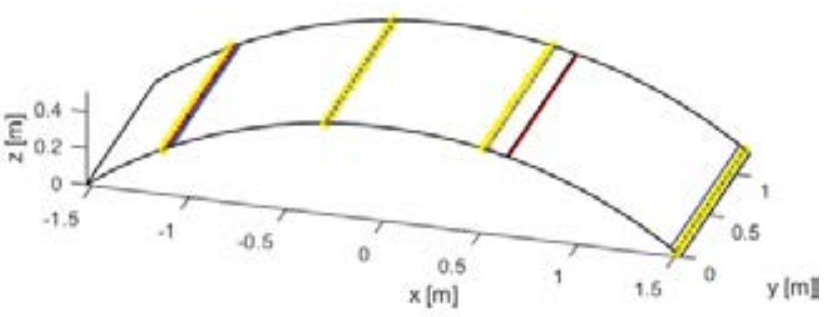

(b) test \#2

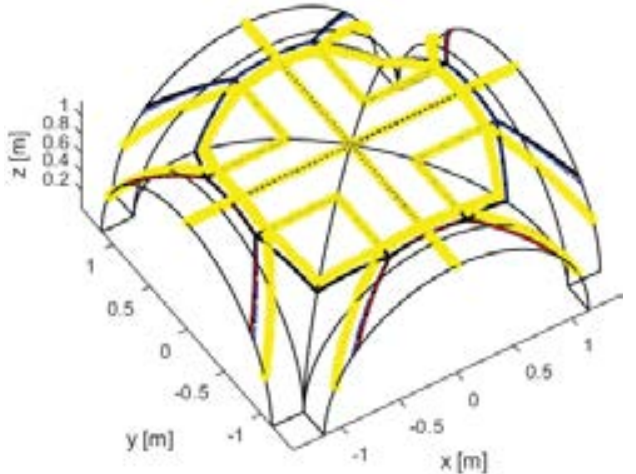

(d) test \#4
ー - - - GA

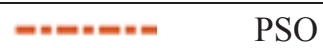 FA

Figure 5. Final crack patterns associated to the collapse mechanisms for the four benchmark tested in [52], one of them re-discussed here (test \#3), obtained by applying four different meta-heuristic approaches to a NURBS-based limit analysis scheme: (a) circular skew arch test \#1, (b) parabolic straight arch test \#2, (c) skew barrel vault test \#3, (d) ribbed cross vault test \#4. 
Test

$\# 1$

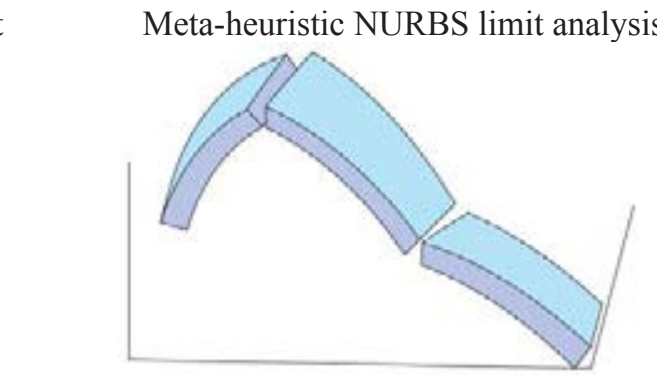

Ultimate failure load: $19.4 \mathrm{kN}$

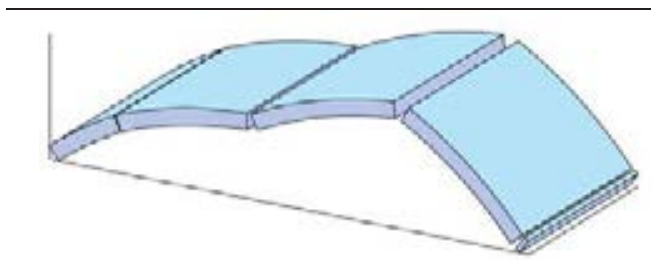

Ultimate failure load: $40.9 \mathrm{kN}$

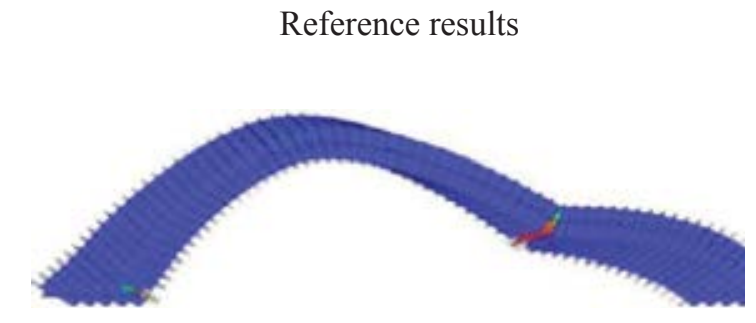

FE limit analysis: $18.8 \mathrm{kN}$ Experimental failure load: $17.4 \mathrm{kN}$

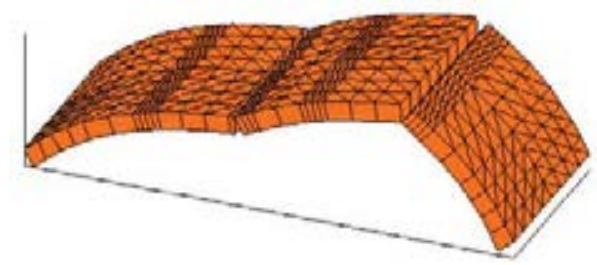

FE limit analysis: $37.0 \mathrm{kN}$ Experimental failure load: $40.2 \mathrm{kN}$

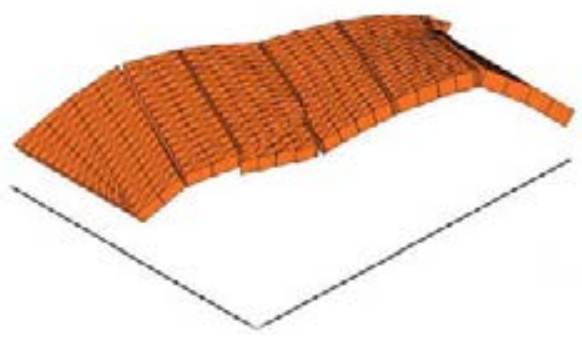

FE limit analysis: $33.0 \mathrm{kN}$ Experimental failure load: $26.0 \mathrm{kN}$

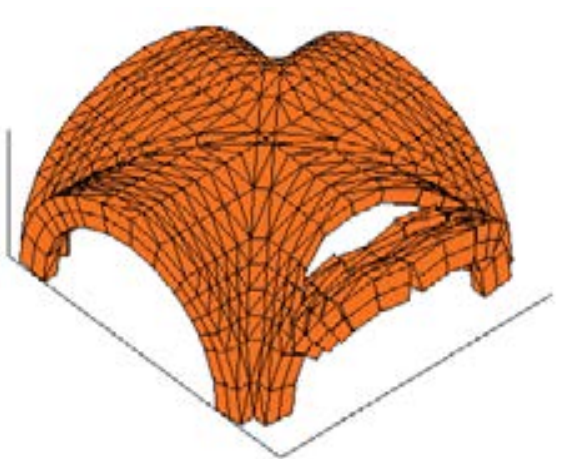

FE limit analysis: $14.2 \mathrm{kN}$

Experimental failure load: $12.9 \mathrm{kN}$

Figure 6. Comparison between the collapse mechanisms obtained in [52] by means of the proposed metaheuristic NURBS-based limit analysis approach and the ones obtained in the literature through both homogenized finite element limit analysis and experiments. 
Table 1. Summary of results obtained in [52] for four different benchmarks on curved structures

\begin{tabular}{|c|c|c|c|c|c|c|c|}
\hline \multirow[b]{2}{*}{ Test\# } & \multirow[b]{2}{*}{ Algorithm } & \multirow{2}{*}{$\begin{array}{l}\text { Computing } \\
\text { time }[\mathrm{s}]\end{array}$} & \multirow{2}{*}{$\begin{array}{l}\text { Collapse load } \\
\text { multiplier } \Gamma\end{array}$} & \multirow{2}{*}{$\begin{array}{l}\text { \# Function } \\
\text { evaluations }\end{array}$} & \multicolumn{3}{|c|}{ 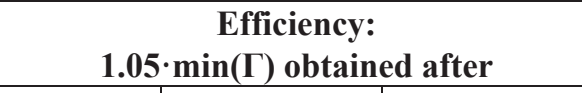 } \\
\hline & & & & & $\begin{array}{l}\text { \# itera- } \\
\text { tions }\end{array}$ & time $[\mathrm{s}]$ & $\begin{array}{c}\text { \# func- } \\
\text { tion evalua- } \\
\text { tions }\end{array}$ \\
\hline \multirow{4}{*}{1} & GA & 63 & 20.449 & 765 & $>50$ & $>63$ & $>765$ \\
\hline & PSO & 55 & 19.389 & 765 & 6 & 7 & 105 \\
\hline & FA & 57 & 19.607 & 765 & 11 & 13 & 180 \\
\hline & PPA & 60 & 19.377 & 858 & 2 & 3 & 45 \\
\hline \multirow{4}{*}{2} & GA & 47 & 45.626 & 1020 & $>50$ & $>47$ & $>1020$ \\
\hline & PSO & 46 & 40.895 & 1020 & 8 & 8 & 180 \\
\hline & FA & 53 & 43.150 & 1020 & $>50$ & $>53$ & $>1020$ \\
\hline & PPA & 54 & 40.901 & 1164 & 3 & 4 & 84 \\
\hline \multirow{4}{*}{3} & GA & 509 & 26.936 & 2040 & 11 & 112 & 480 \\
\hline & PSO & 512 & 27.329 & 2040 & 19 & 195 & 800 \\
\hline & FA & 537 & 28.219 & 2040 & 26 & 279 & 1080 \\
\hline & PPA & 570 & 27.083 & 2324 & 7 & 82 & 335 \\
\hline \multirow{4}{*}{4} & GA & 3408 & 13.960 & 1020 & 46 & 3133 & 940 \\
\hline & PSO & 3441 & 13.733 & 1020 & 4 & 275 & 100 \\
\hline & FA & 2998 & 16.302 & 1020 & $>50$ & $>2998$ & $>1020$ \\
\hline & PPA & 3715 & 13.733 & 1154 & 7 & 541 & 168 \\
\hline
\end{tabular}

\subsection{FE model with few DOFS and non-linear analyses}

Once the optimized position of fracture lines has been found, the NURBS mesh is imported in a FE software where non-linear static and dynamic analyses can be performed. A FE model governed by few degrees of freedom (dofs) is built starting from the NURBS geometry by using a properly defined subroutine [61]. Each shell rigid element is converted into a mesh of elastic tetrahedral finite elements (12 dofs for each one). Then, cohesive-frictional contactbased interfaces are automatically inserted in the cracks of the collapse mechanism formerly obtained. In alternative, plastic damaging strips can be used as well, according to the general scheme depicted in Figure 1. Such failure criterion has been implemented in Abaqus through an automatic user-defined subroutine but any FE code can be utilized for such purpose. In this way, a non-linear constitutive law under interface tangential and tensile stresses is imposed along the contact-based interfaces. Moreover, the potential effects of masonry crushing failure 
can be accounted for inside the macro-blocks assuming for their constituent material any nonlinear continuum plastic-damage constitutive law. For Abaqus, for instance, the standard concrete damaged plasticity (CDP) model appears very suited and has been considered in the simulations reported in this paper, see [62][63] for the constitutive laws adopted.

An incremental-evolutive approach is adopted to derive the full load-displacement curves of any kind of masonry structure. It is important to observe that, having non-linearities mainly are imposed just at the contact-based interfaces, the computational burden required by this $\mathrm{FE}$ model is much lower in comparison with fully non-linear FE models. At the same time, any mesh dependency effect is avoided thanks to the previous adaptive limit analysis that allows defining the exact position of the cracks. The procedure, initially proposed for out-of-plane loaded walls, has been recently extended to in-plane loaded walls and 3D buildings [61]. Figure 7 shows a schematization of the proposed procedure (corresponding to step 2 of the full procedure depicted in Figure 1).

Alternatively, the FE model can be realized by following an approach [50] based on discrete elements recently proposed for masonry vaults in [64]. This allows extending the twosteps procedure for double curvature masonry elements.

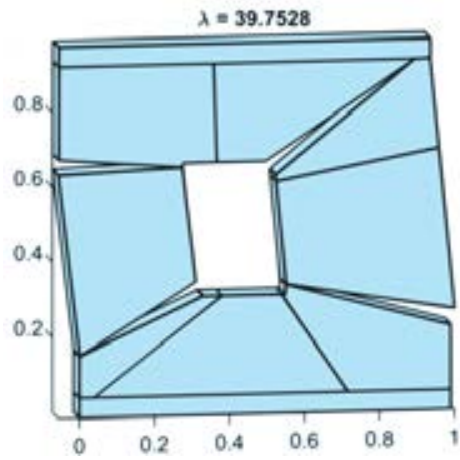

(a)

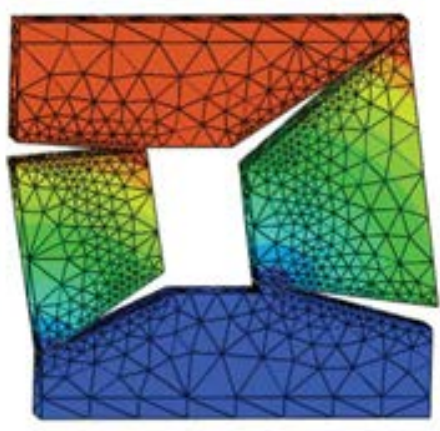

(b)

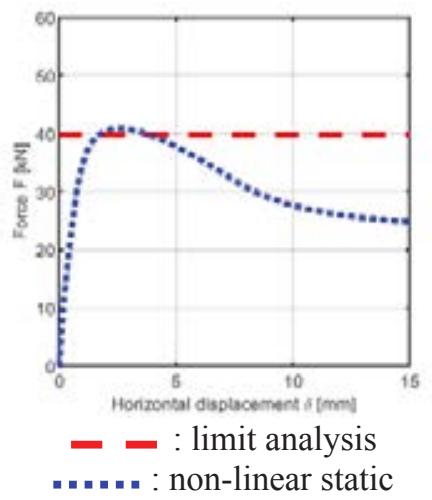

(c)

Figure 7. Step 2: non-linear static analysis with few dofs: (a) collapse mechanism obtained form limit analysis, (b) FE model derived from the NURBS model, (c) collapse load multiplier and pushover curve.

\section{NUMERICAL EXAMPLES}

Some numerical examples involving monumental masonry constructions are here presented.

The first structure considered is the Church of Natività di Maria Vergine, in Bondeno (Italy), a single nave church with lateral chapels (Figure 8a), approximately 36 meters long and 22 meters wide. The façade is 19 meters high and is built with a typical Romanesque style. The original plant dates back to the Middle Age (1100), but exception made for the apse and the bell tower, the rest was re-built more recently, from the end of 1600 to the end of 1800 . The medieval semi-octagonal apse is covered by irregular ribbed gothic cross vaults, which are original of that period. Vaults are realized with thin single leaf common clay bricks.

Numerical results can be obtained by representing the whole construction with few NURBS elements. Mechanical properties for clay bricks and mortar joints masonry have been adopted according to prescriptions contained in the Italian code: in particular, a vanishing tensile stress is adopted, with a cohesion of the non-linear interfaces and friction angle equal to $0.06 \mathrm{MPa}$ and $22^{\circ}$ (corresponding to a friction coeffiecient equal to 0.4 ) respectively. 

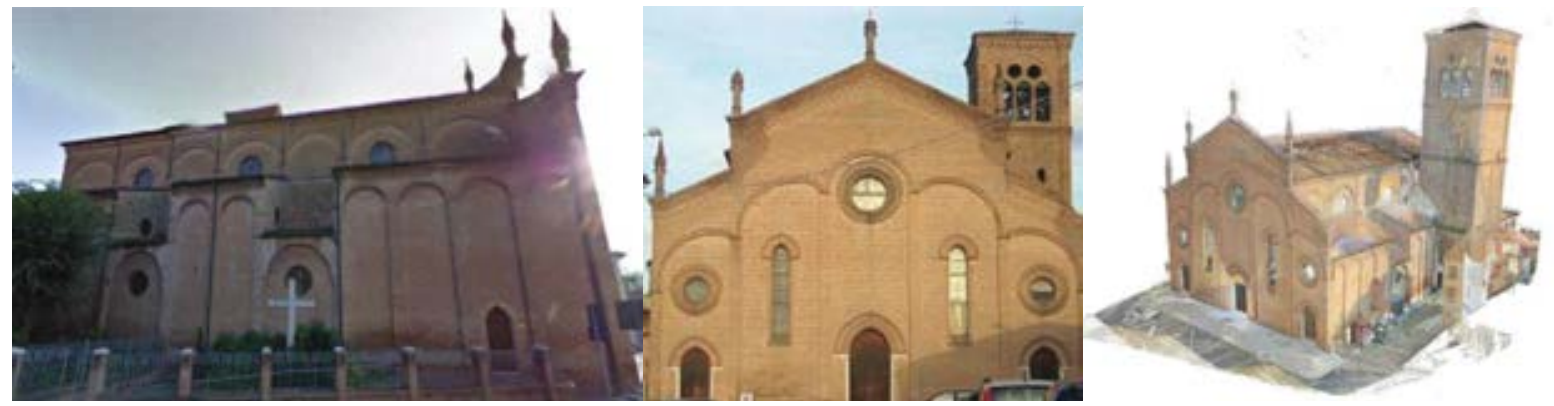

(a)

Façade, out-of-plane, weak connection

Façade, out-of-plane, good con-

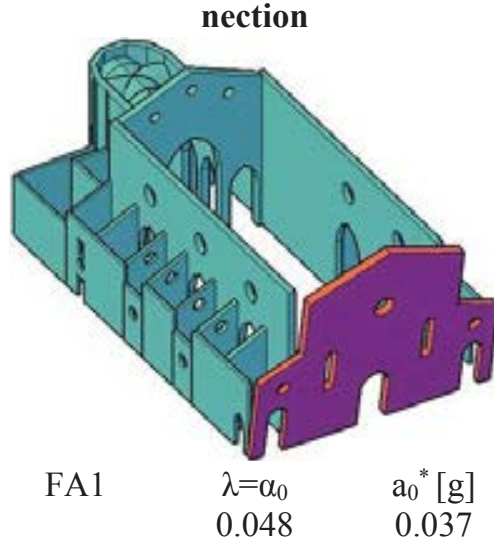

Tympanum, out-of-plane I
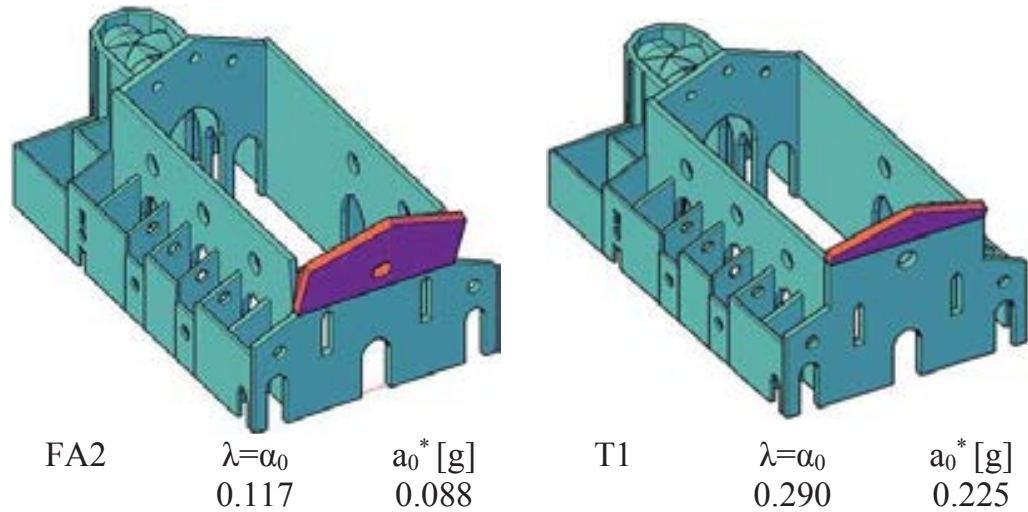

Tympanum, out-of-plane II

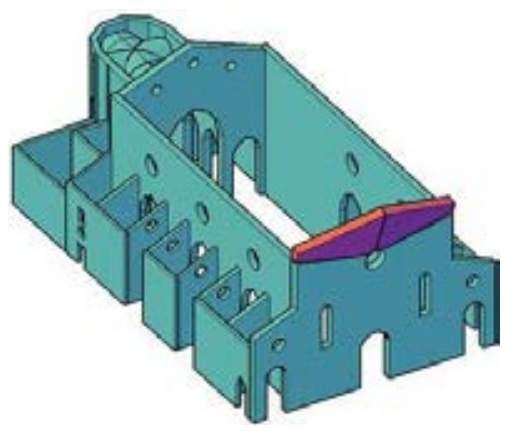

Triumphal arch, out-of-plane

Triumphal arch, in-plane
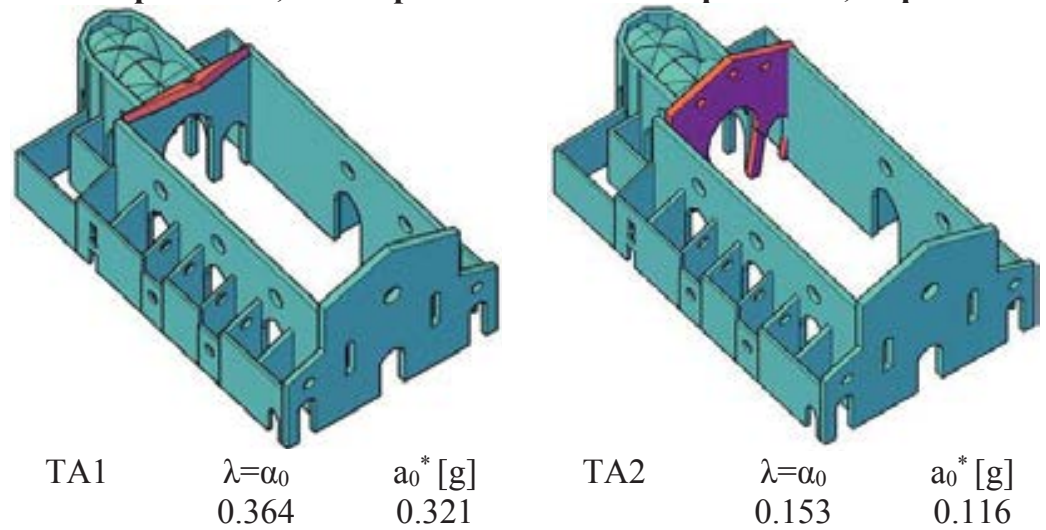

$\mathrm{T} 2$

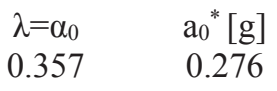

Lateral walls I, out-of-plane
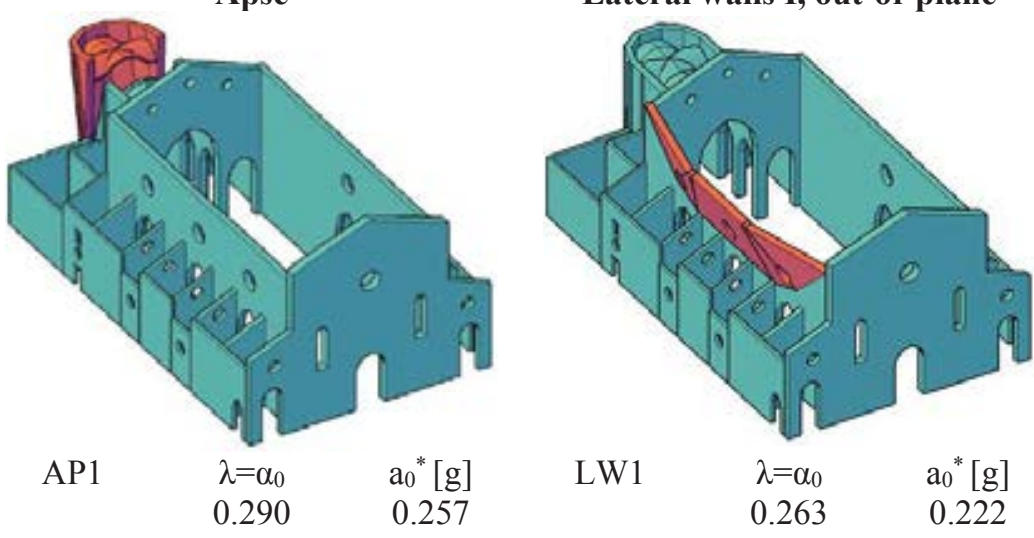

TA2

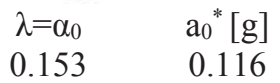

Lateral walls, out-of-plane

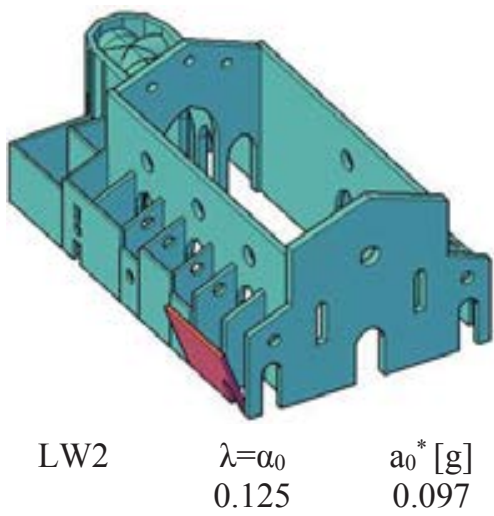

(b)

Figure 8. (a) The Church of Natività di Maria Vergine in Bondeno (Italy), (b) failure mechanisms obtained through adaptive limit analysis assuming different directions of the seismic action and interlocking between walls. 
A compression strength cap equal to $2.4 \mathrm{MPa}$ has been also used. As prescribed, these values have been furtherly reduced according to a factor equal to 1.35 . In the present simulations, a constant horizontal force distribution along the height of the building is assumed.

The resultant failure mechanisms are depicted in Figure 8b. In the same figure, for the sake of completeness, values of $\alpha_{0}$ and $a_{0}^{*}$ are also reported, where $\alpha_{0}$ is the horizontal load multiplier $\lambda$ from limit analysis and $a_{0} *$ the corresponding spectral acceleration (normalized against g). In general, the obtained mechanisms are in good agreement with the pre-assigned failures suggested by the Italian Guidelines for the Cultural Heritage.

The second example here presented is the seismic behavior of the dome of the Church of Anime Sante, which was severely damaged on $6^{\text {th }}$ April 2009 during the L'Aquila seismic sequence (maximum seismic event with the following characteristic: $\mathrm{Mw}=6.3, \mathrm{ML}=5.8$ ). Attributed to Giuseppe Valadier, the dome (Figure 9a) was completed in parallel with the realization of the church in 1805 . After the earthquake, both the lantern and the dome collapsed, and the still standing parts of the drum and the dome are visible from photos reported in Figure 9b.

Some simulation results under the application of two distributions of horizontal loads, one linear and the other constant along the height, are here presented. Even in this case, in absence of specific data to assign to masonry mechanical properties, resistance values have been chosen in agreement with the Italian code for existing buildings: null value of tensile stress, 2.4 $\mathrm{MPa}$ for compression strength, $0.06 \mathrm{MPa}$ for cohesion and $22^{\circ}$ degrees for interfaces friction angle.

The results obtained in terms of both collapse mechanisms and normalized acceleration are reported in Figure 9c. The failure mechanism does not change too much with the distribution of horizontal loads applied, conversely the collapse acceleration is very sensitive to the actual distribution of accelerations. It is interesting to observe that the still standing portion of dome and drum obtained through the NURBS limit analysis reproduces quite closely the situation observed after L'Aquila earthquake.

The identification of such a clear collapse mechanism is also useful to perform non-linear static analyses by simply re-meshing the structure with elastic elements and non-linear interfaces where the yield lines are located (as described in the previous Section). This procedure is followed in the benchmark discussed next. 


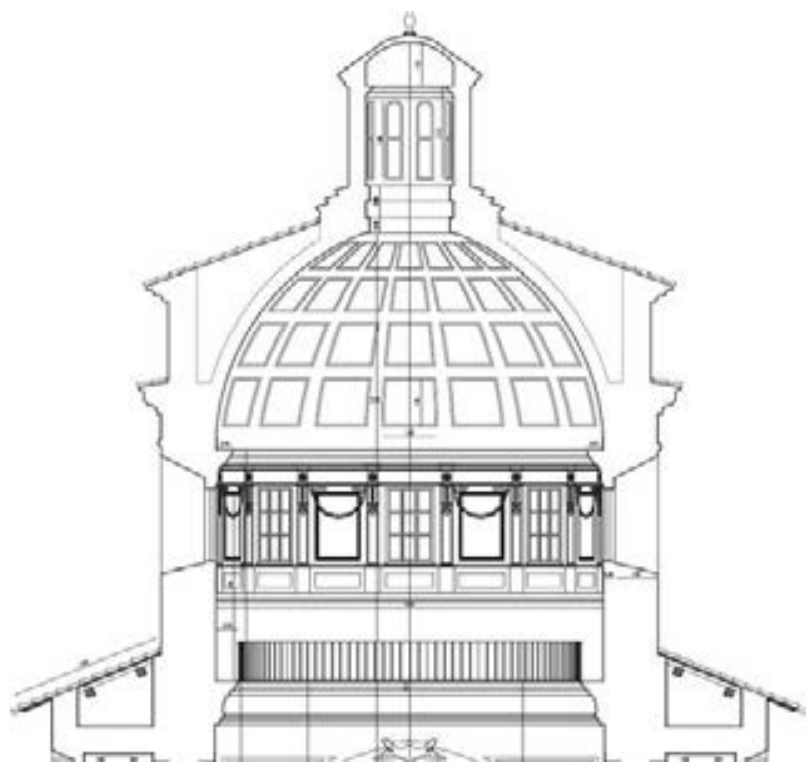

(a)

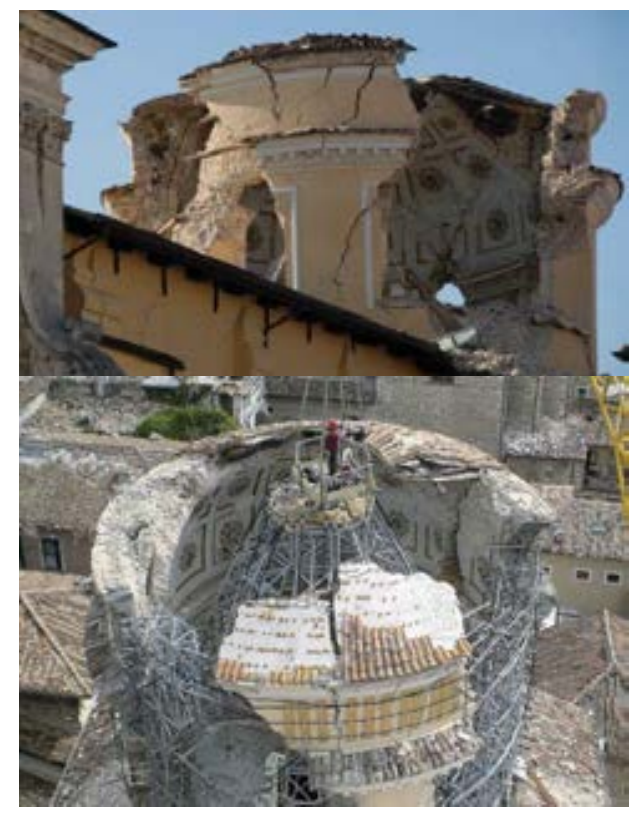

(b)
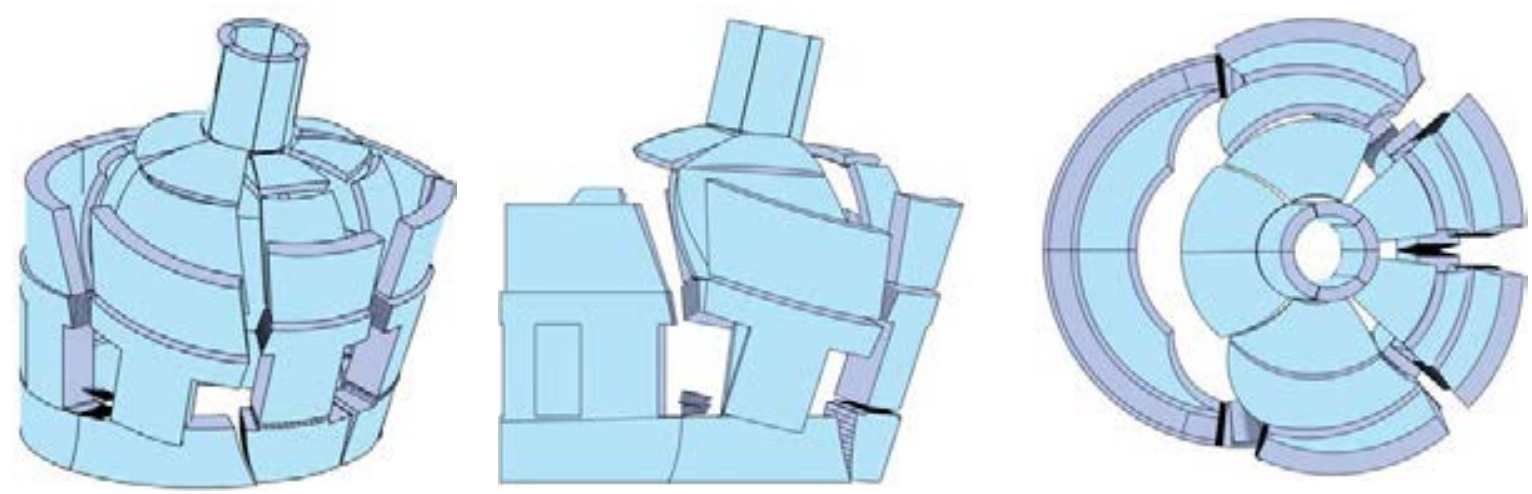

Configuration of acceleration: linear in height

Normalized collapse acceleration $\left(\mathrm{ag}_{\mathrm{g}} / \mathrm{g}\right): 0.237$
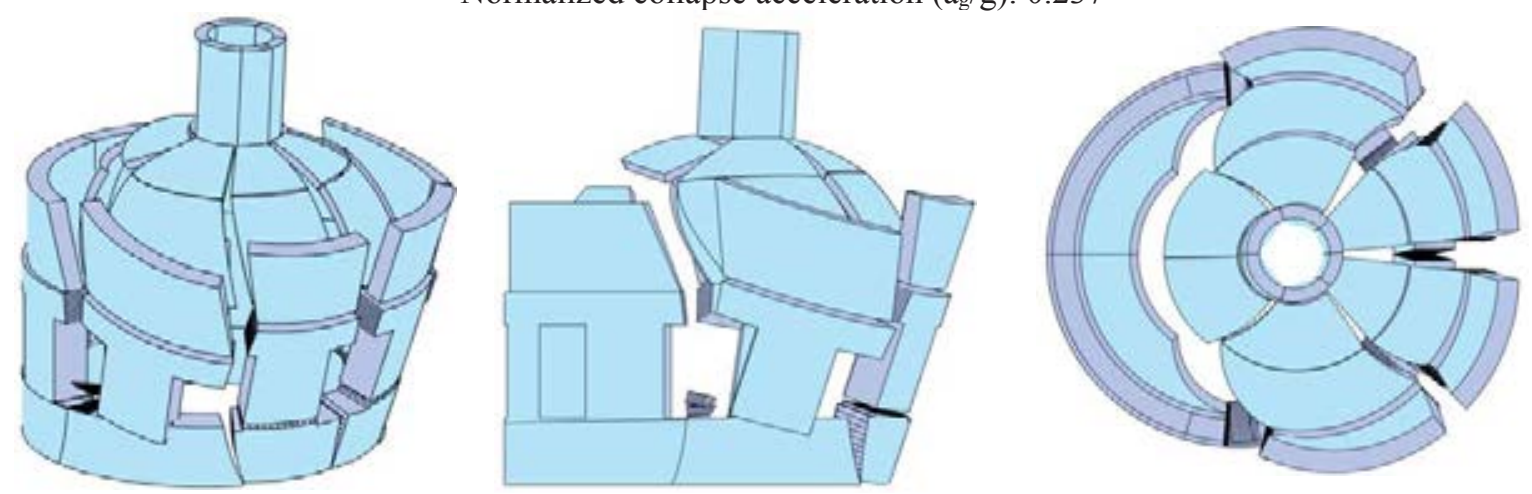

Configuration of acceleration: constant in height

Normalized collapse acceleration $\left(\mathrm{a}_{\mathrm{g}} / \mathrm{g}\right)$ : 0.354

(c)

Figure 9. Dome of the Anime Sante Church, in L'Aquila (Italy): (a) geometry before the earthquake, (b) still standing parts after the collapse, (c) collapse mechanisms obtained under linear and constant in height horizontal acceleration (perspective, lateral and plan views). 


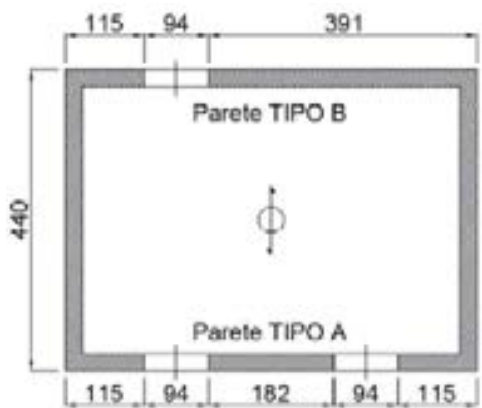

LCA

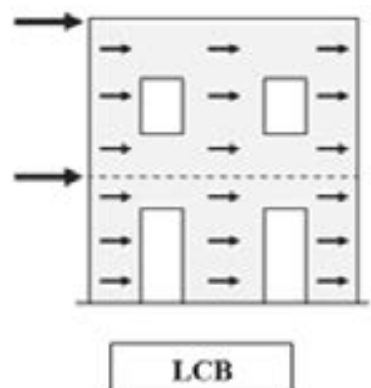

(a)
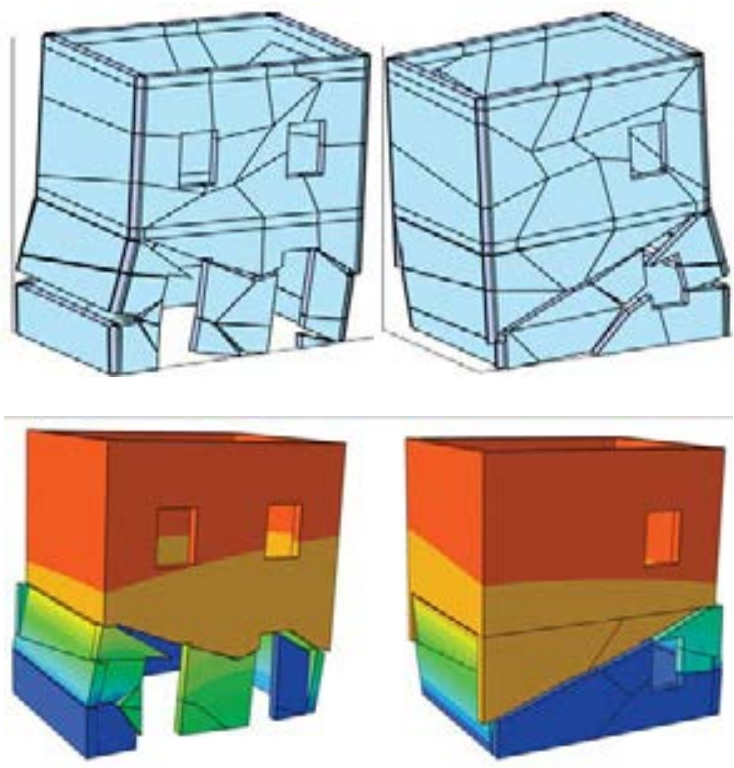

(c)

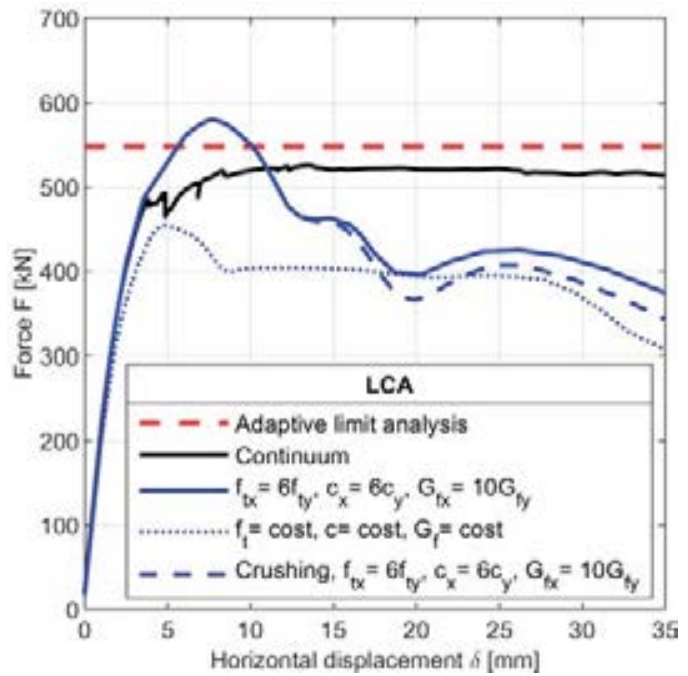

(d)

(b)

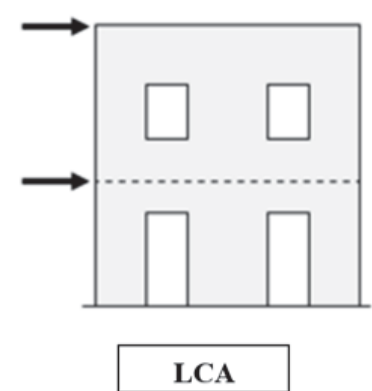

LCB
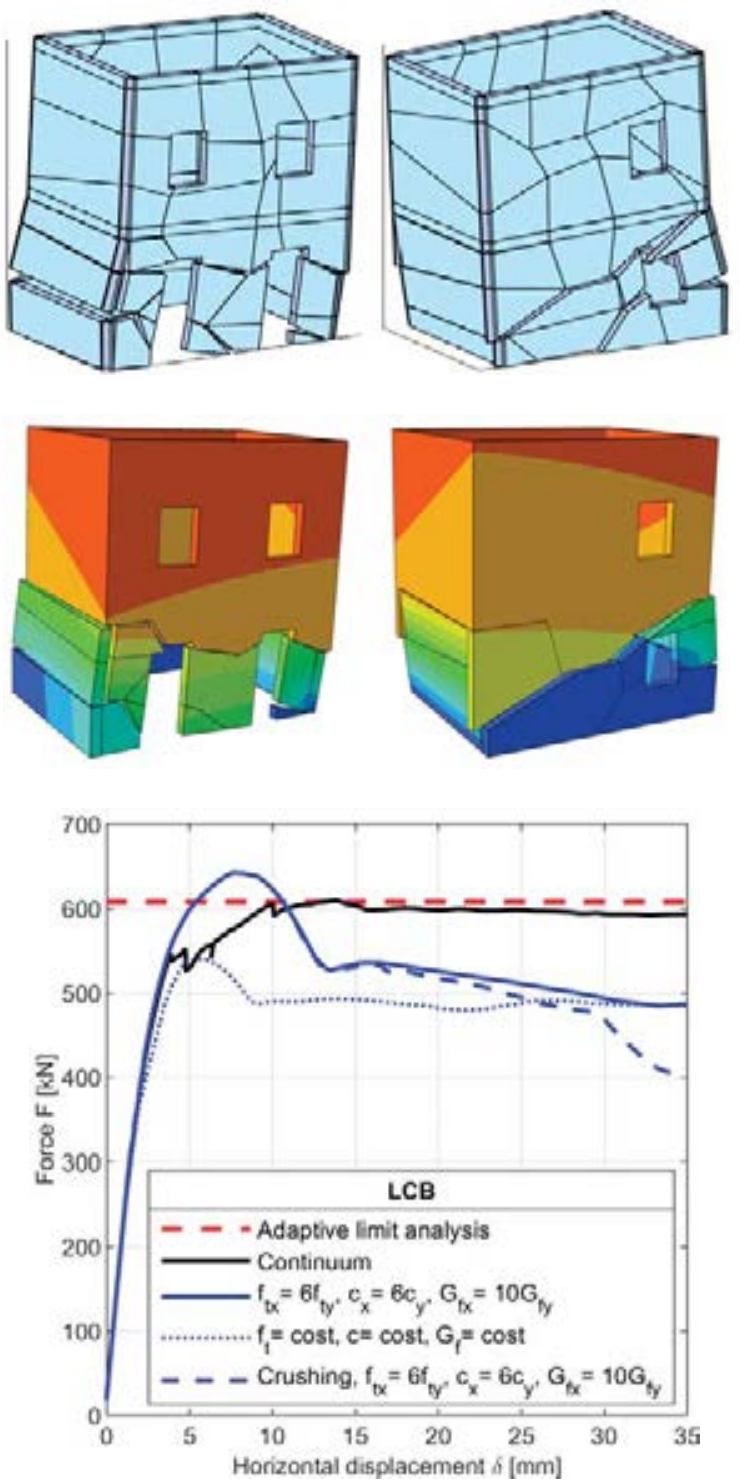

Figure 10. Two-storey masonry building: (a) geometry and load conditions, (b) collapse mechanisms obtained through limit analysis, (c) non-linear static deformed shape, and (d) comparison of results (in b-d, LCA on the left and LCB on the right).

Such benchmark relies on the application of the aforementioned two-step procedure to a simple laboratory two-storey masonry building. As depicted in Figure 10a, the horizontal projection of the construction is completely described by the 4 perimeter walls, each one $0.25 \mathrm{~m}$ 
thick. Some openings are present on the two longitudinal walls. Both storeys are characterized by rigid horizontal floors, carried by the longitudinal walls and connected by concrete edgings. From here ongoing the longitudinal direction term will be referred to that direction parallel to the long walls (i.e. the horizontal direction in Figure 10a). The vertical load given by the floors is equal to $10 \mathrm{kN} / \mathrm{m}^{2}$. It is worth mentioning that this benchmark has been extensively analyzed by the authors within a research project supported by the Italian network of University laboratories of seismic engineering (ReLUIS).

The small two-storey house is analyzed under the application of two different horizontal load distributions, directed along the longitudinal direction (i.e. parallelly to the longest walls) and labelled as LCA and LCB. LCA is characterized by horizontal forces concentrated at floor levels, whereas LCB by distributed forces along the height of the structure (see Figure 10a). A NURBS model of this full-scale 3D case study has been realized. Limit analyses have been performed by assuming $0.04 \mathrm{MPa}$ as tensile strength $f, 6.2 \mathrm{MPa}$ as compression strength $f_{\mathrm{c}}$, a cohesion $c$ equal to $0.163 \mathrm{MPa}$ and a friction coefficient for the interfaces equal to 0.58 . Moreover, a specific weight equal to $17.5 \mathrm{kN} / \mathrm{m}^{3}$ has been also adopted. With the aim of providing a more realistic representation of the masonry behavior in shear, a non-associative flow rule has been used in this example. The final results obtained are depicted in Figure 10b$\mathrm{d}$ in terms of collapse mechanism and collapse base shear. It can be observed that cracks spread mainly on piers at the ground floor, where both flexural damage and sliding cracks appear on all four perimeter walls.

Non-linear static analyses on the derived FE model are now presented. Four hypotheses have been considered as regards material properties: (i) linear material with constant contact properties, i.e. the same resistance values assigned in limit analysis plus contact fracture energy $G_{\mathrm{f}}=500 \mathrm{~N} / \mathrm{m}$, (ii) linear material with variable contact properties, for which $f_{\mathrm{tx}}=6 f_{\mathrm{t}}, f_{\mathrm{ty}}=f_{\mathrm{t}}$, $G_{\mathrm{fx}}=6 G_{\mathrm{f}}, G_{\mathrm{fy}}=G_{\mathrm{f}}, c_{\mathrm{x}}=6 c, c_{\mathrm{y}}=c$, (iii) variable contact properties as above and material with finite compressive strength (called "crushing" model in what follows), and (iv) continuum approach introduced for comparison.

The results of the present modeling procedure (Figure 10c) show a good agreement with the base shear values obtained with limit analysis and with those obtained through a continuum approach, in terms of both pushover curves (presented in Figure 10d) and damage pattern (the continuum damage pattern is not shown here for sake of brevity). Concerning the postpeak response, the continuum model exhibits a plateau, while a considerable softening is shown by the variants of the proposed approach, which is further accentuated in the case with crushing. Accordingly, the proposed approach appears significantly robust and able to account for a softening behavior without particular numerical issues.

The proposed procedure resulted computationally efficient, particularly if compared to standard continuum FE models. Therefore, the adaptive NURBS limit analysis combined suitably with a FE non-linear static analysis can be considered an effective and efficient tool for the seismic assessment of historic and monumental masonry buildings. 


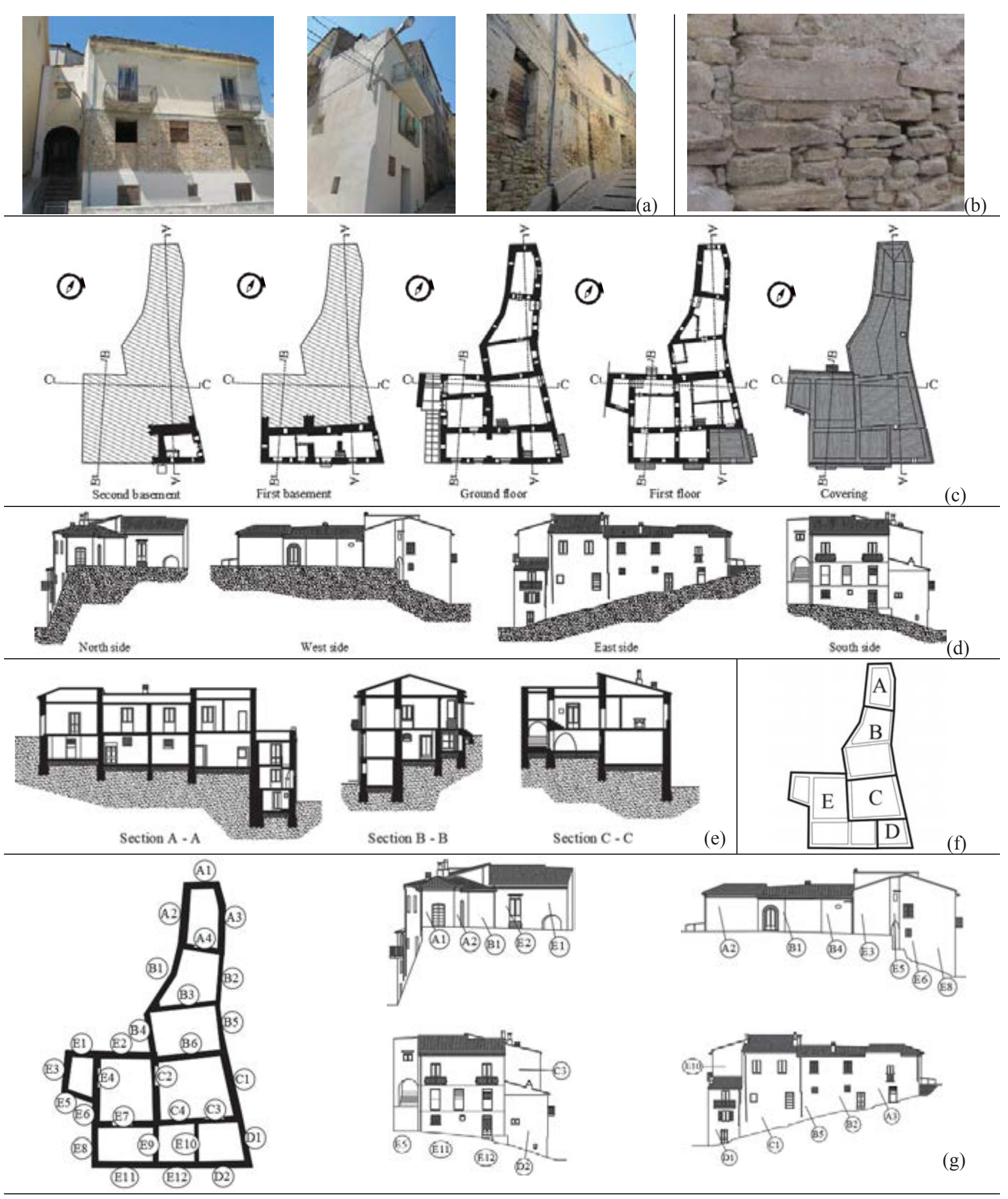

Figure 11. Aggregate "La Vecchia Forestale": (a) pictures of South and East sides, (b) particular of the irregular masonry texture, (c) plan views, (d) perspective views, (e) sections, (f) identification and notation of structural units, and $(\mathrm{g})$ nomenclature here adopted for each wall.

The fourth numerical example deals with a masonry aggregate called "La Vecchia Forestale" (Figure 11). In Figure 11 (a) some pictures of the aggregate are reported. The 
building is characterized by an irregular masonry texture, composed of irregular stones and low quality mortar, as it can be seen on several masonry walls (see Figure 11(b)). The maximum length is about $25 \mathrm{~m}$, which is referred to the East side, whereas, in the orthogonal direction, the width is almost equal to $14.2 \mathrm{~m}$ for the South side and $3.8 \mathrm{~m}$ for the North side. Strong irregularities can be observed both in plan and elevation. There is a total of four floors, two of which are basements defining different foundation levels. The maximum and the minimum height are respectively equal to $11.8 \mathrm{~m}$ on the East side and $3.9 \mathrm{~m}$ in the North-West corner, both measured in relation to the local ground level. The plan of different levels, perspective views, and some sections are reported in Figure 11(c-e). Five different structural units, which have been named by using the letters from A to E, have been identified. In Figure 11(f), the distinction of each structural unit is depicted: only units C, D, and E are residential, whereas units A and B are used as storage rooms. Different types of horizontal floors are present and no chains or concrete edgings are reported: the roof is made with light wood elements.

Finally, in Figure 11(g) the notation here adopted for each wall is reported. Basically, each wall is named with a letter, representing the unit to which it belongs, and a number: therefore, for example, $\mathrm{A} 1$ is the wall number 1 belonging to structural unit $\mathrm{A}$.

Figure 12 shows the analyses on structural unit A considering two directions of the horizontal load; a relatively good interlocking between perpendicular walls is considered. In Figure 12(a) the horizontal load has been applied along the North direction. As it can be seen, the collapse occurs through the overturning of wall A1 together with some triangular portions of the transversal walls A2 and A3. Moreover, a vertical fracture line opens on wall A1: such a fracture line is probably due to the different geometries of walls A2 and A3, resulting in a non-symmetrical contribution to the failure mechanism. A value of $\alpha_{0}$ equal to 0.772 has been obtained for the horizontal load multiplier, which is much higher when compared with the simple overturning of wall A1. Such a result is mainly due to the internal dissipation in tension and shear related to the formation of inclined fracture lines, a consequence of the good interlocking hypothesis. In Figure 12(b) the horizontal load has been applied along the East direction. In this case, the final result mainly consists of an overturning of the out-of-plane loaded wall including a single triangular portion of the transversal wall A1. Since wall A4 is thinner than wall A1, the fracture line is almost vertical and therefore no triangular blocks from this element are involved in the mechanism. Despite the similarities with the simple overturning of wall A3 evaluated in [56], a value of $\alpha_{0}$ equal to 0.319 has been obtained: such higher value is due to the internal dissipation included in the computations.

In Figure 13 the analysis of structural unit B is reported. A total of 4 walls has been selected, as it can be seen in the plan view. The walls adjacent to other structural units have been supposed as disconnected in the contact-edge. Therefore, only one of the out-of-plane loaded walls is involved in the collapse mechanisms. The collapse takes place through an overturning of wall B2 along an inclined fracture line, due to the different constraint conditions applied on the vertical edges of wall B2 (good connection with walls B3 and B5, no connection with walls A4 and A3). The associated $\alpha_{0}$ is equal to 0.156. 


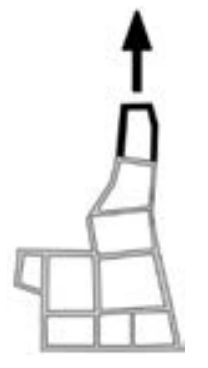

$\alpha_{0}=0.772$

$\mathrm{a}_{0} *=0.623 \mathrm{~g}$

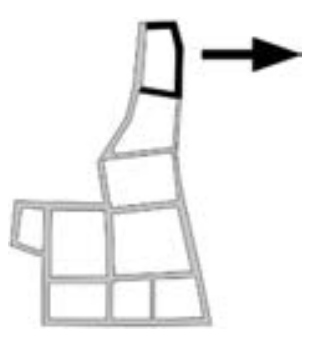

$\alpha_{0}=0.319$

$\mathrm{a}_{0} *=0.210 \mathrm{~g}$

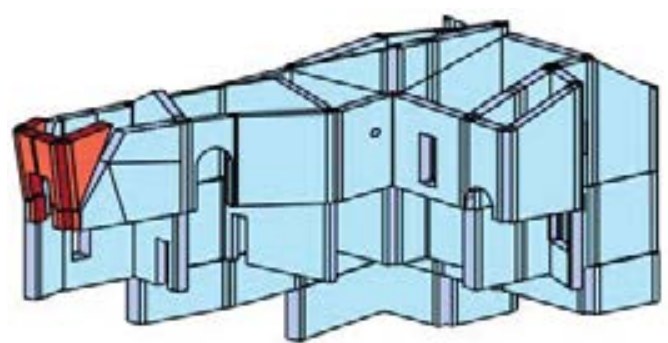

(a)

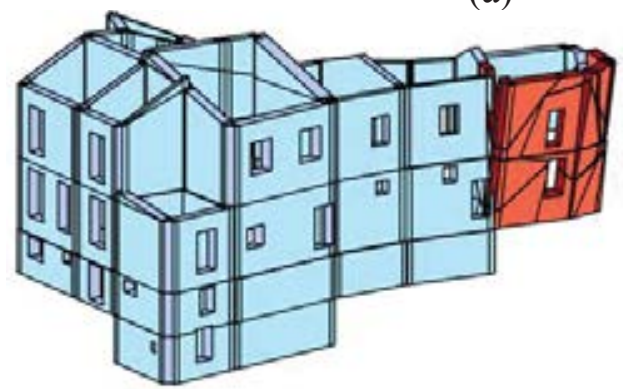

(b)

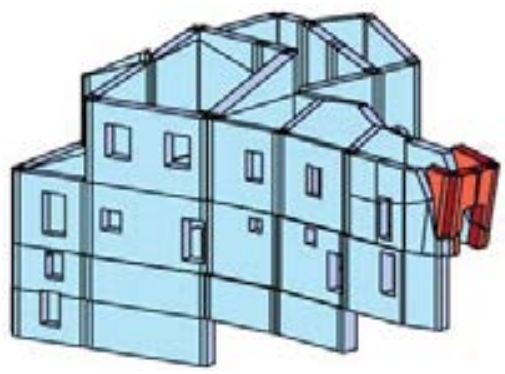

Figure 12. Aggregate, unit A, analyses with good interlocking: horizontal load applied along (a) the North and (b) the East directions.

A similar behavior has been observed for wall C1, as it can be seen in Figure 14. Even in this case, wall $\mathrm{C} 1$ is well connected only to the transversal wall $\mathrm{C} 3$. The collapse mechanism is again an overturning with inclined fracture line: however, in this case the fracture line starts at the bottom of the last storey. This is due to the lower thickness of wall C3 at the last storey with respect to the bottom part, resulting in a partial participation of this weaker portion of wall C3 in the failure mechanism.
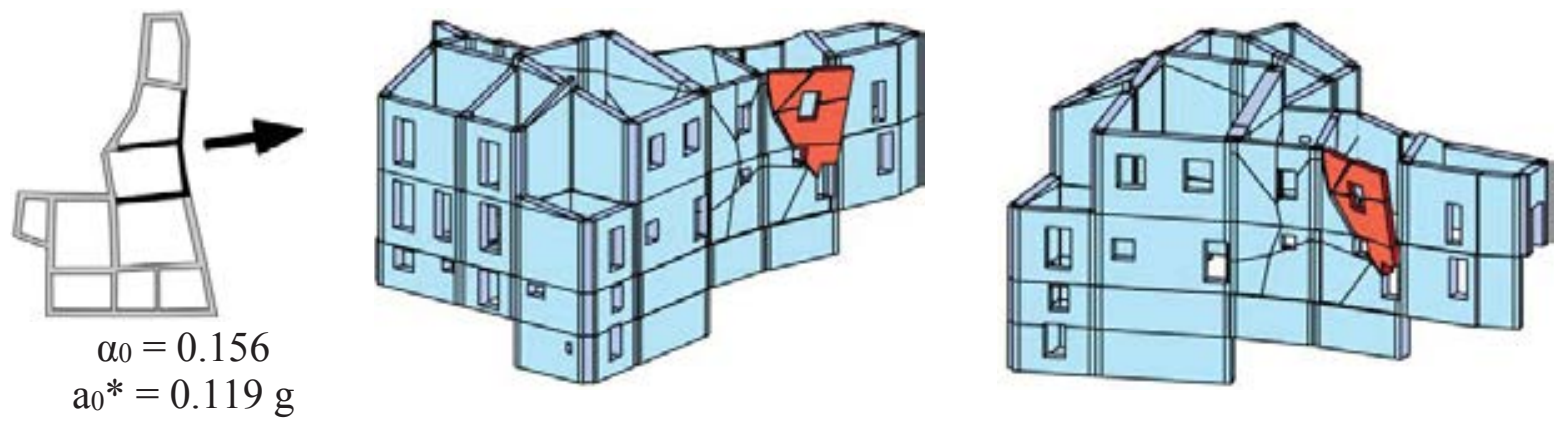

Figure 13. Aggregate, unit B, analyses with good interlocking.

Similar results are obtained for units D and E, not reported here for the sake of conciseness. The interested reader is referred to [56] for further details. 

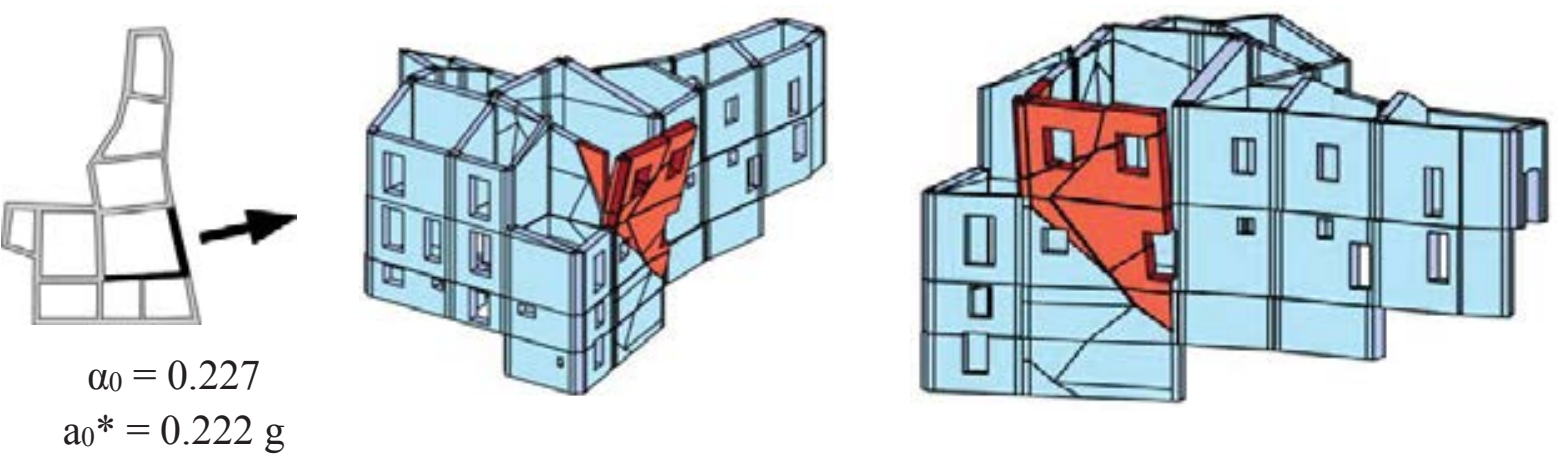

Figure 14. Aggregate, unit C, analyses with good interlocking.

As final example, a quite complex 3D limit analysis approach conceived for monumental constructions characterized by complex curved shapes is here presented. This approach consists of a limit analysis in which the structure is discretized through NURBS solids. A NURBS solid is a closed region of space delimited by NURBS boundary surfaces. NURBS solids are used to represent the rigid elements involved in the mechanism. By using NURBS surfaces to describe the external boundary of each block, this approach allows extending the study to structures that do not behave as shell-like elements, thus resulting as a generalization of the kinematic limit analysis for curved three-dimensional rigid block structures.

The Carmo Convent, in Lisbon (Portugal), is here analyzed through the NURBS solidsbased limit analysis. The conventual church, see Figure 15a, presents a Gothic style composed of a nave, two longitudinal aisles, one transept, a main chapel and four side chapels, distributed onto a Latin cross. Considering the huge complexity of the case, the analysis is here focused on the triumphal arch located in the transept. Some structural elements cannot be properly represented without a NURBS solid representation: Gothic arches present a nonrectangular and curved cross-section, whereas limestone columns have a multi-circular crosssection.

The transept is analyzed under the application of an out-of-plane directed horizontal load. A comparison with FE non-linear static analyses previously presented by Scacco and colleagues [65] is also shown. Materials parameters have been assumed in agreement with those indicated in [65]. In particular a compression strength equal to $27 \mathrm{MPa}$, a friction angle equal to $30^{\circ}$, a cohesion equal to $0.05 \mathrm{MPa}$, and null tensile strength are adopted. Similarly to the example of the masonry dome, a constant (Load Case 1, LC1) and a linear along the height (Load Case 2, LC2) distribution of horizontal accelerations are considered. In addition, kinematic non-linear analyses aimed at including a softening behavior in tension (initial tensile strength of $0.15 \mathrm{MPa}$, fracture energy equal to $0.015 \mathrm{~N} / \mathrm{mm}$ ) are performed using a sequential linear programming approach where displacements at the end of the simulations are found with a procedure fully described in [66].

The results obtained are reported in Figure 15b. The failure mechanism involves the overturning of the central columns with the participation of arches at the top. Moreover, arches at the top show a combined in- and out-of-plane mechanism. A load multiplier equal to $1.19 \cdot 10^{-1}$ has been found for LC1 distribution. The resultant horizontal loads at collapse normalized for the total weight (i.e. the load multiplier) are compared with the pushover curve derived in [65], finding again a very good agreement even in such very complex case where the geometry reproduction of the sections is particularly demanding.

With this last example, it can be affirmed that the presented approach is promising in terms of efficiency and reliability to perform limit and non-linear static analysis for complex exist- 
ing masonry buildings, historical structures and monumental constructions, even when very complex 3D massive curved geometries are present.

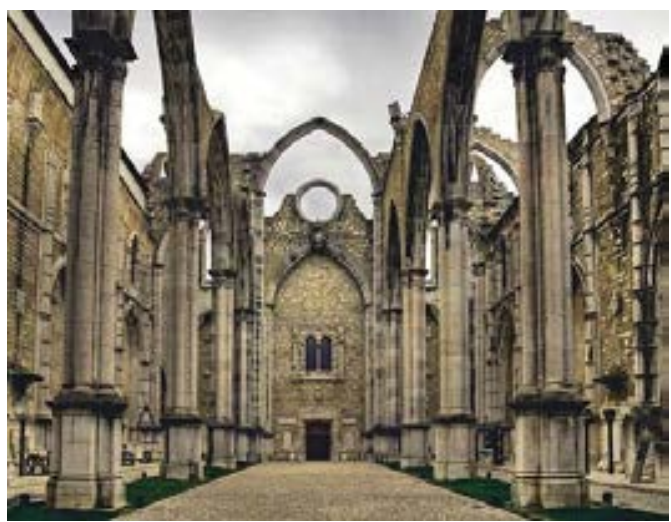

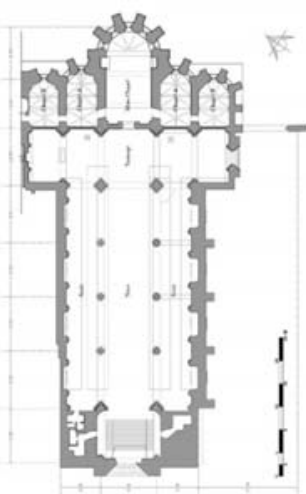

(a)
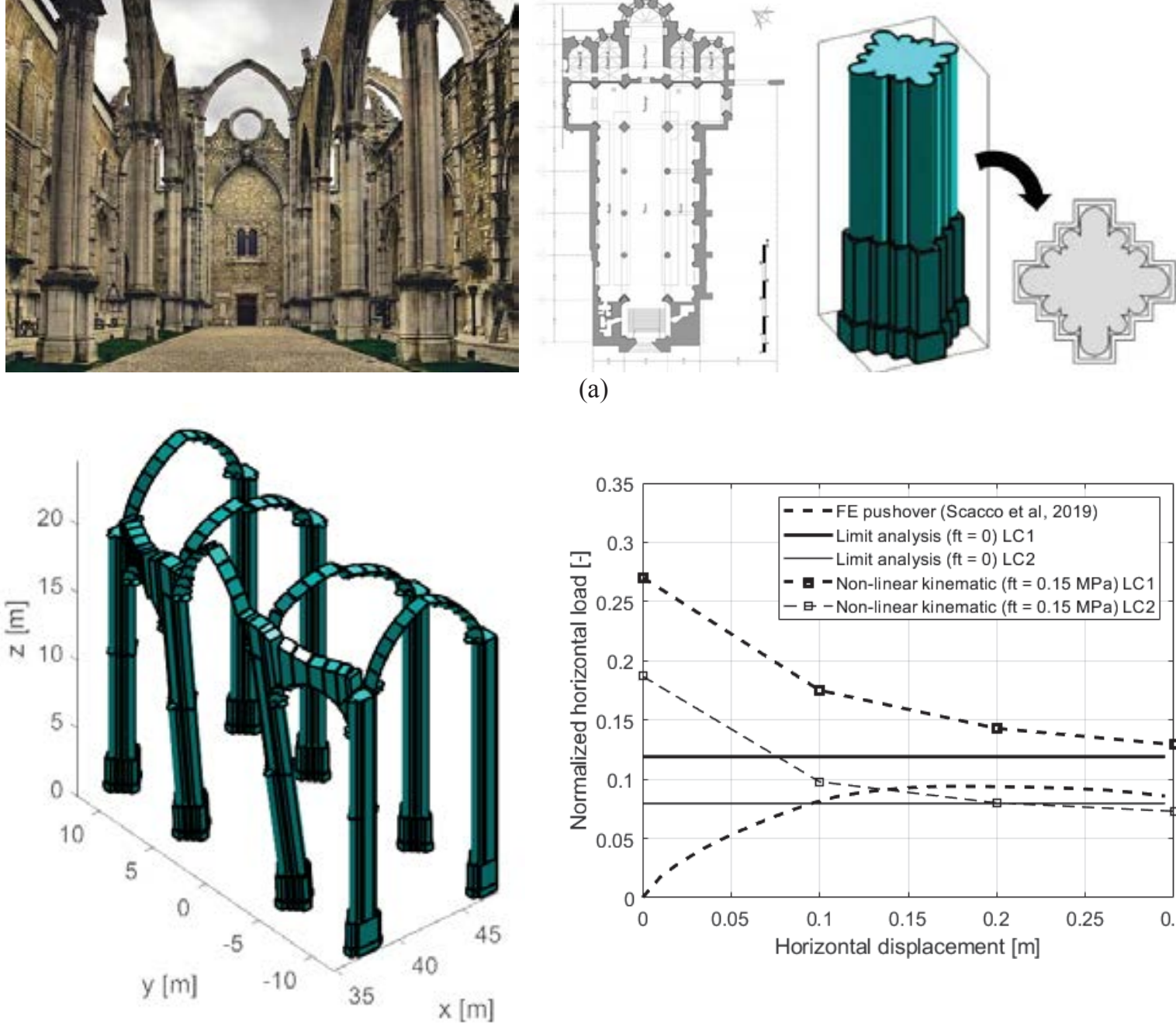

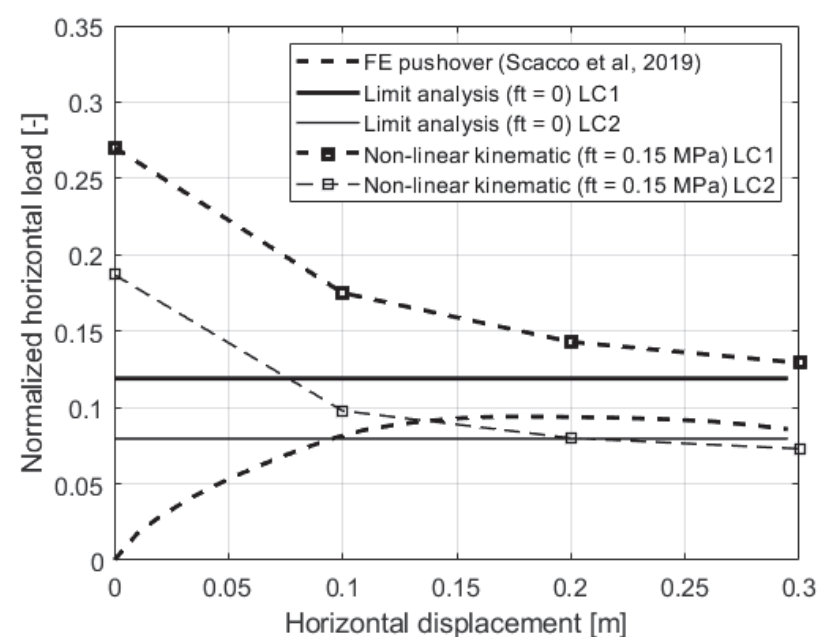

(b)

Figure 15. Analysis of the transept of the Carmo Convent (Lisbon, Portugal): (a) photo of the church as it appears now, plane view and multi-circular column in the transept, (b) collapse mechanism and results compared with previous FE non-linear static analyses reported in [65].

\section{CONCLUSIONS}

The present research paper was intended to show a short synopsis of the results obtained by the authors in the evaluation of the ultimate load bearing capacity and the non-linear static behavior of complex historical or existing masonry structures using non conventional software. Such approach is based on a two-step procedure, where the structures are first analyzed in the limit analysis case with adaptive 2D and 3D NURBS meshes and then with non-linear FEs where non linearity is lumped on the crack patterns found using the adaptive limit analysis. A particularly interesting recent improvement of the approach proposed is the utilization of 3D NURBS and Sequential Linear programming to predict also displacements during the formation of the failure mechanism, as shown in the last example (Carmo Convent in Lisbon). Future research streams will include (but they will not limited to) the adaptive NURBS limit analysis of massive historical masonry structures (e.g. towers and pagodas) and the extension 
to non-linear dynamic loads, which include not only seismic actions but also extreme events such as explosions and floods.

\section{REFERENCES}

[1] A. M. D'Altri, V. Sarhosis, G. Milani, J. Rots, S. Cattari, S. Lagomarsino, E. Sacco, A. Tralli, G. Castellazzi and S. de Miranda, "Modeling strategies for the computational analysis of unreinforced masonry structures: review and classification," Archives of Computational Methods in Engineering, vol. 27, pp. 1153-1185, 2020.

[2] M. Malena, F. Portioli, R. Gagliardo, G. Tomaselli, L. Cascini and G. de Felice, "Collapse mechanism analysis of historic masonry structures subjected to lateral loads: A comparison between continuous and discrete models," Computers \& Structures, vol. 220, pp. 14-31, 2019.

[3] J. Heyman, "The stone skeleton," International Journal of Solids and Structures, vol. 2, no. 2, p. 249-279, 1966.

[4] M. Angelillo, "Static analysis of a Guastavino helical stair as a layered masonry shell," Composite Structures, vol. 119, p. 298-304, 2015.

[5] F. Marmo and L. Rosati, "Reformulation and extension of the thrust network analysis," Computers \& Structures, vol. 182, p. 104-118, 2017.

[6] P. Block and J. Ochsendorf, "Thrust network analysis: A new methodology for threedimensional equilibrium," Journal of the International Association for shell and spatial structures, vol. 48, no. 3, pp. 167-173, 2007.

[7] F. Fraternali, "A thrust network approach to the equilibrium problem of unreinforced masonry vaults via polyhedral stress functions," Mechanics Research Communications, vol. 37, no. 2, p. 198-204, 2010.

[8] A. Iannuzzo, A. Dell'Endice, T. Van Mele and P. Block, "Numerical limit analysis-based modelling of masonry structures subjected to large displacements," Computers \& Structures, vol. 242, p. 106372, 2021.

[9] F. Portioli, C. Casapulla, M. Gilbert and L. Cascini, "Limit analysis of 3D masonry block structures with non-associative frictional joints using cone programming," Computers \& Structures, vol. 143, p. 108-121, 2014.

[10]C. Baggio and P. Trovalusci, "Limit analysis for no-tension and frictional threedimensional discrete systems," Journal of Structural Mechanics, vol. 26, no. 3, pp. 287304, 1998.

[11] M. Rossi, C. Calderini, B. Di Napoli, L. Cascini and F. Portioli, "Structural analysis of masonry vaulted staircases through rigid block limit analysis," Structures, vol. 23, pp. 180-190, 2020.

[12] G. Milani, “3D Upper Bound Limit Analysis of Multi-Leaf Masonry Walls," International Journal of Mechanical Sciences, vol. 50, no. 4, p. 817-836, 2008.

[13] G. Milani and P. Lourenço, "A simplified homogenized limit analysis model for randomly assembled blocks out-of-plane loaded," Computers \& Structures, vol. 88, p. 690-717, 2010.

[14]A. Cavicchi and L. Gambarotta, "Two-dimensional finite element upper bound limit analysis of masonry bridges," Computers \& structures, vol. 84, no. 31-32, pp. 2316-2328, 2006.

[15] S. Sloan and P. Kleeman, "Upper Bound Limit Analysis Using Discontinuous Velocity Fields," Computer Methods in Applied Mechanics and Engineering, vol. 127, no. 1-4, pp. 293-314, 1995 
[16] G. Milani, P.B. Lourenço "A discontinuous quasi-upper bound limit analysis approach with sequential linear programming mesh adaptation," International Journal of Mechanical Sciences, vol. 51, no. 1, pp. 89-104, 2009.

[17] G. Milani, "Upper bound sequential linear programming mesh adaptation scheme for collapse analysis of masonry vaults," Advances in Engineering Software, vol. 79, p. 91-110, 2015.

[18]A. Chiozzi, G. Milani and A. Tralli, "A Genetic Algorithm NURBS-based new approach for fast kinematic limit analysis of masonry vaults," Computers \& Structures, vol. 182, p. 187-204, 2017.

[19] A. Chiozzi, G. Milani, N. Grillanda and A. Tralli, "A fast and general upper-bound limit analysis approach for out-of-plane loaded masonry walls," Meccanica, vol. 53, no. 7, pp. 1875-1898, 2018.

[20] M. Godio and K. Beyer, "Evaluation of force-based and displacement-based out-of-plane seismic assessment methods for unreinforced masonry walls through refined model simulations," Earthquake Engineering \& Structural Dynamics, vol. 48, no. 4, p. 454-475, 2018.

[21] C. Chácara, F. Cannizzaro, B. Pantò, I. Caliò and P. B. Lourenço, "Seismic vulnerability of URM structures based on a Discrete Macro-Element Modeling (DMEM) approach," Engineering Structures, vol. 201, p. 109715, 2019.

[22] S. Lagomarsino, A. Penna, A. Galasco and S. Cattari, "TREMURI program: An equivalent frame model for the nonlinear seismic analysis of masonry buildings," Engineering Structures, vol. 56, p. 1787-1799, 2013.

[23] N. Chieffo, F. Clementi, A. Formisano and S. Lenci, "Comparative fragility methods for seismic assessment of masonry buildings located in Muccia (Italy)," Journal of Building Engineering, vol. 25, p. art. no. 100813, 2019.

[24] G. Chiumiento and A. Formisano, "Simplified and refined analyses for seismic investigation of historical masonry clusters: Comparison of results and influence of the structural units position," Frontiers in Built Environment, vol. 5, p. art. no. 84, 2019.

[25] A. Formisano and A. Massimilla, "A Novel Procedure for Simplified Nonlinear Numerical Modeling of Structural Units in Masonry Aggregates," International Journal of Architectural Heritage, vol. 12, no. 7-8, pp. 1162-1170, 2018.

[26] A. Formisano and A. Marzo, "Simplified and refined methods for seismic vulnerability assessment and retrofitting of an Italian cultural heritage masonry building," Computers and Structures, vol. 180, pp. 13-26, 2017.

[27] D. Malomo and M. J. DeJong, "A Macro-Distinct Element Model (M-DEM) for simulating the in-plane cyclic behavior of URM structures," Engineering Structures, vol. 227, p. $111428,2021$.

[28] D. Baraldi and A. Cecchi, "Discrete Approaches for the Nonlinear Analysis of in Plane Loaded Masonry Walls: Molecular Dynamic and Static Algorithm Solutions," European Journal of Mechanics - A/Solids, vol. 57, p. 165-177, 2016.

[29] A.M. D'Altri, F. Messali, J. Rots, G. Castellazzi and S. de Miranda, "A damaging blockbased model for the analysis of the cyclic behaviour of full-scale masonry structures," Engineering Fracture Mechanics, vol. 209, pp. 423-448, 2019.

[30] R. Serpieri, M. Albarella and E. Sacco, "A 3D Microstructured Cohesive-frictional Interface Model and Its Rational Calibration for the Analysis of Masonry Panels," International Journal of Solids and Structures, vol. 122-123, p. 110-127, 2017.

[31] L. Cascini, F. Portioli and R. Landolfo, "3D Rigid block micro-modelling of a full-scale unreinforced brick masonry building using mathematical programming," International Journal of Masonry Research and Innovation, vol. 1, no. 3, pp. 189-206, 2016. 
[32] M. Angelillo, A. Fortunato, A. Gesualdo, A. Iannuzzo and G. Zuccaro, "Rigid block models for masonry structures," International Journal of Masonry Research and Innovation, vol. 3, no. 4, pp. 349-368, 2018.

[33] D. Addessi and E. Sacco, "Nonlinear analysis of masonry panels using a kinematic enriched plane state formulation," International Journal of Solids and Structures, vol. 90, pp. 194-214, 2016.

[34] M. Petracca, L. Pelà, R. Rossi, S. Oller, G. Camata and E. Spacone, "Regularization of first order computational homogenization for multiscale analysis of masonry structures," Computational Mechanics, vol. 57, no. 2, pp. 257-276, 2015.

[35] M. Valente, G. Milani, E. Grande and A. Formisano, "Historical masonry building aggregates: advanced numerical insight for an effective seismic assessment on two row housing compounds," Engineering Structures, vol. 190, pp. 360-379, 2019.

[36] T. Forgács, V. Sarhosis and K. Bagi, "Influence of construction method on the load bearing capacity of skew masonry arches," Engineering Structures, vol. 168, no. 1, pp. 612$627,2018$.

[37] A. Ferrante, F. Clementi and G. Milani, "Advanced numerical analyses by the NonSmooth Contact Dynamics method of an ancient masonry bell tower," Mathematical Methods in the Applied Sciences, vol. 43, no. 13, pp. 7706-7725, 2020.

[38] J. Lemos, "Contact representation in rigid block models of masonry," International Journal of Masonry Research and Innovation, vol. 4, no. 321-334, p. 2, 2017.

[39]F. Clementi, A. Ferrante, E. Giordano, F. Dubois and S. Lenci, "Damage assessment of ancient masonry churches stroked by the Central Italy earthquakes of 2016 by the nonsmooth contact dynamics method," Bulletin of Earthquake Engineering, vol. 18, no. 2, pp. 455-486, 2020.

[40] V. Sarhosis and J. Lemos, "A detailed micro-modelling approach for the structural analysis of masonry assemblages," Computers and Structures, vol. 206, no. 1, pp. 66-81, 2018.

[41] V. Sarhosis, S. Garrity and Y. Sheng, "Influence of brick-mortar interface on the mechanical behaviour of low bond strength masonry brickwork lintels," Engineering Structures, vol. 88 , no. 1 , pp. 1-11, 2015.

[42] G. Uva, V. Tateo and S. Casolo, "Presentation and validation of a specific RBSM approach for the meso-scale modelling of in-plane masonry-infills in RC frames," International Journal of Masonry Research and Innovation, vol. 5, no. 3, pp. 366-395, 2020.

[43]Ž. Nikolić, H. Smoljanović and N. Živaljić, "Numerical analysis of masonry structures by finite-discrete element model," International Journal of Masonry Research and Innovation, vol. 1, no. 4, pp. 330-350, 2016.

[44] V. Sarhosis, K. Tsavdaridis and I. Giannopoulos, "Discrete element modelling of masonry infilled steel frames with multiple window openings subjected to lateral load variations," Open Construction and Building Technology Journal, vol. 8, no. 1, pp. 93-103 , 2014.

[45] V. Gazzani, M. Poiani, F. Clementi, G. Milani and S. Lenci, "Modal parameters identification with environmental tests and advanced numerical analyses for masonry bell towers: a meaningful case study," Procedia Structural Integrity, vol. 11, pp. 306-313, 2018.

[46] A. Ferrante, D. Loverdos, F. Clementi, G. Milani, A. Formisano, S. Lenci and V. Sarhosis, "Discontinuous approaches for nonlinear dynamic analyses of an ancient masonry tower," Engineering Structures, vol. 230, p. 111626, 2021.

[47]F. Clementi, G. Milani, A. Ferrante, M. Valente and S. Lenci, "Crumbling of Amatrice clock tower during 2016 Central Italy seismic sequence: Advanced numerical insights," Frattura Ed Integrità Strutturale, vol. 14, no. 51, p. 313-335, 2019. 
[48] M. Pepe, M. Pingaro, P. Trovalusci, E. Reccia and L. Leonetti, "Micromodels for the inplane failure analysis of masonry walls: Limit analysis, FEM and FEM/DEM approaches," Frattura e Integrità Strutturale, vol. 14, no. 51, pp. 504-516, 2020.

[49] D. Baraldi, E. Reccia and A. Cecchi, "In plane loaded masonry walls: DEM and FEM/DEM models. A critical review,” Meccanica, vol. 53, no. 7, pp. 1613-1628, 2018.

[50] A.M. D'Altri, S. de Miranda, G. Milani and G. Castellazzi, "A numerical procedure for the force-displacement description of out-of-plane collapse mechanisms in masonry structures," Computers \& Structures, vol. 233, \#106234, 2020.

[51] N. Grillanda, A. Chiozzi, G. Milani, A. Tralli, "Tilting plane tests for the ultimate shear capacity evaluation of perforated dry joint masonry panels. Part II: Numerical analyses," Eng Struct, vol. 228, \#111460, 2021. doi:10.1016/j.engstruct.2020.111460.

[52] N. Grillanda, A. Chiozzi, G. Milani, A. Tralli, "Efficient meta-heuristic mesh adaptation strategies for NURBS-based upper-bound limit analysis of general curved threedimensional masonry structures," Computers and Structtures vol. 236, \#106271, 2020. doi:10.1016/j.compstruc.2020.106271.

[53] A. Chiozzi, N. Grillanda, G. Milani, A. Tralli, "UB-ALMANAC: An adaptive limit analysis NURBS-based program for the automatic assessment of partial failure mechanisms in masonry churches," Engineering Failure Analysis, vol. 85, pp. 201-220, 2018. doi:10.1016/j.engfailanal.2017.11.013.

[54] N. Grillanda, A. Chiozzi, G. Milani, A. Tralli, "On Collapse Behavior of Reinforced Masonry Domes under Seismic Loads," Key Engineering Materials, vol. 817, pp. 275-282, 2019. doi:10.4028/www.scientific.net/KEM.817.275.

[55] N. Grillanda, M. Valente, G. Milani, A. Chiozzi, A. Tralli, "Advanced numerical strategies for seismic assessment of historical masonry aggregates," Engineering Structures, vol. 212, \#110441, 2020. doi:10.1016/j.engstruct.2020.110441.

[56] N. Grillanda, M. Valente, G. Milani, "ANUB-Aggregates: a fully automatic NURBSbased software for advanced local failure analyses of historical masonry aggregates," Bulletin of Earthquake Engineering, vol. 18, pp. 3935-2961, 2020. doi:10.1007/s10518020-00848-6.

[57] A. Giuffrè, "Safety and conservation of historical centes: the case of Ortigia", Laterza, Rome, 1993, (in Italian).

[58]L. Piegl, W. Tiller, “The NURBS Book,” Berlin: Springer; 1995. doi:10.1007/978-3-64259223-2.

[59] G. Milani, P.B. Lourenco, A. Tralli, "Homogenised limit analysis of masonry walls, Part I: failure surfaces," Computers and Structures, vol., no. (3-4), pp. 166-180, 2006.

[60]E. Milani, G. Milani, A. Tralli, "Limit analysis of masonry vaults by means of curved shell finite elements and homogenization," International Journal of Solids and Structures, vol, 45, pp. 5258-5288, 2008. doi:10.1016/j.ijsolstr.2008.05.019.

[61] A.M. D’Altri, N. Lo Presti, N. Grillanda, G. Castellazzi, S. de Miranda, G. Milani, “A two-step automated procedure based on adaptive limit and pushover analyses for the seismic assessment of masonry structures", Computers and Structures, in press, 2021. doi: 10.1016/j.compstruc.2021.106561

[62] J. Lubliner, J. Oliver, S. Oller, E. Oñate, “A plastic-damage model for concrete,” International Journal of Solids and Structures, vol. 25, pp. 299-326, 1989.

[63] J. Lee, G.L. Fenves, "Plastic-Damage Model for Cyclic Loading of Concrete Structures," Journal of Engineering Mechanics, vol. 124, pp. 892-900, 1998.

[64] J. Scacco, G. Milani, P.B. Lourenço, "Automatic mesh generator for the non-linear homogenized analysis of double curvature masonry structures", Advances in Engineering Software, vol., 150, \#102919, 2020. doi:10.1016/j.advengsoft.2020.102919. 
[65] J. Scacco, G. Salazar, N. Bianchini, N. Mendes, C. Cullimore, L. Jain, "Seismic assessment of the church of Carmo convent," in Proc. of the Congress on Métodos Numéricos em Eng., 2019.

[66]A. Tralli, A. Chiozzi, N. Grillanda, G. Milani, "Masonry structures in the presence of foundation settlements and unilateral contact problems," International Journal of Solids and Structures, vol. 191-192, pp. 187-201, 2020. 